\title{
Application of Presplitting Blasting Technology in Surrounding Rock Control of Gob-Side Entry Retaining with Hard Roof: A Case Study
}

\author{
Shuang Gong $\mathbb{D}^{1},{ }^{1,2,3}$ Yi Tan ${ }^{\mathbb{D}},{ }^{1,2}$ Yunpeng Liu, ${ }^{4}$ Dan $\mathrm{Zhu}^{4},{ }^{4}$ and Yang Yu ${ }^{5,6,7}$ \\ ${ }^{1}$ State Key Laboratory of Water Resource Protection and Utilization in Coal Mining, Beijing 100011, China \\ ${ }^{2}$ School of Energy Science and Engineering, Henan Polytechnic University, Jiaozuo 454000, China \\ ${ }^{3}$ Henan Key Laboratory for Green and Efficient Mining \& Comprehensive Utilization of Mineral Resources, \\ Jiaozuo 454000, China \\ ${ }^{4}$ North China Company, SINOPEC, Zhengzhou,450006, China \\ ${ }^{5}$ School of Surveying and Land Information Engineering, Henan Polytechnic University, Henan Jiaozuo 454000, China \\ ${ }^{6}$ China Institute of Geo-Environmental Monitoring, Beijing 100081, China \\ ${ }^{7}$ Key Laboratory of Mine Ecological Effects and Systematic Restoration, Ministry of Natural Resources, Beijing 100081, China
}

Correspondence should be addressed to Yi Tan; 517237667@qq.com and Yang Yu; yuyang2005@139.com

Received 25 August 2021; Accepted 29 September 2021; Published 15 October 2021

Academic Editor: Zhengyang Song

Copyright (c) 2021 Shuang Gong et al. This is an open access article distributed under the Creative Commons Attribution License, which permits unrestricted use, distribution, and reproduction in any medium, provided the original work is properly cited.

\begin{abstract}
Through the analysis of the mining situation and geological data of Qidong mine and working face, the key factors affecting the roof cutting and pressure relief roadway retention along the goaf are defined. Combined with numerical simulation and field test, the reasonable parameters of combined presplitting blasting of deep hole and shallow hole in hard roof are determined, and the roof cutting effect is tested through field observation and borehole peeping. The comprehensive control measures for the surrounding rock of 7135 roadway with roof cutting and pressure relief and gob retaining are formulated, including safety assurance technical measures, such as advanced precrack and seam cutting, roof reinforcement and support, gangue retaining protection beside the roadway, lagging temporary support, and on-site industrial test monitoring scheme. Aiming at the hard rock roof, the "deep hole + shallow hole" presplitting blasting roof cutting technology is developed, and the economic and reasonable blasting parameters are determined. The drilling peep results show that the implementation effect of presplitting blasting technology is good. The results showed that deep holes and shallow holes with small spacing and parallel to each other shall be arranged on the planned seam line. The peeping results show that the crack formation rate in the charging section exceeds $85 \%$ in the process of deep hole blasting. In shallow hole blasting, the crack formation rate of charging section is more than $90 \%$.
\end{abstract}

\section{Introduction}

China and other major coal producing countries have invested more research on the technology of Retaining Roadway along goaf in order to reduce roadway excavation, improve the recovery rate of coal resources, ensure the continuity of production, and improve the economic benefits of mines [1-4]. Previous studies mainly focused on the adaptive conditions of retaining roadway, the deformation and failure mechanism of surrounding rock, the support methods beside roadway and in roadway, and the development of new filling materials.

Zuo et al. have systematically investigated the macro/ meso failure mechanism of deep rock or coal-rock combined body under different loading conditions [5]. Studies of Wang et al. mainly monitored the surrounding rock deformation and coal pillar stress in the recovery rooms of the N1206 panel of 2-2 coal seam at Ningtiaota Coal Mine and the 15205 panel of 5-2 coal seam at Hongliulin Coal Mine [6]. Guo et al. [7] found that at lower stress level, the creep behavior prefers to occur in the samples with smaller 
particles, which is mainly caused by flow of particles without significant particle breakage. As the axial stress increases, the single-sized sample with smaller particle size and the wellgraded sample with larger Talbol power exponent $n$ present more unstable under the constant stress. Wang et al. [8] detailed the state of the art in research on top coal drawing mechanisms in Long wall top coal caving (LTCC) by examining the relevant literature over the past two decades. Wang et al. [9] revealed that the fracturing of the surrounding rock during underwater blasting is due to the combined action of shock and stress waves for the initial rock breakage and subsequent water expansion. Song et al. [10] analyzed the modulus degradation of concrete subjected to multilevel compressive cyclic loading. The evolution of secant elastic modulus is investigated based on measurements from top loading platen and LVDT in the middle part of concrete. The difference value of the two secant elastic moduli is reduced when close to failure could be used as a fatigue failure precursor.

Earlier studies $[11,12]$ used the similar material simulation test method to conduct a preliminary study on the basic roof breaking position and shape of gob retaining roadway, the influence of different support methods on roof activity and relevant technical parameters of roadway side filling. It is considered that the combination of bolt (cable) mesh support and artificial construction of high-strength roadway filling body are conducive to the stability of the roof of gob retaining roadway in comprehensive mechanized top coal caving mining, and the minimum requirements for the width of filling zone and the compressive strength of filling materials are given. According to the masonry beam theory and the basic roof acting on the surrounding rock of the gobside entry of fully mechanized top coal caving in a given deformation mode, some studies [13-15] analyzed the deformation mechanism of the surrounding rock of the roadway, established the mechanical model of the roadway top coal, preliminarily analyzed and solved the deformation of the top coal under the given deformation of the basic roof using the variational method, and analyzed the top coal subsidence and support resistance of coal elastic modulus. The relationship between roadway width is discussed. Through actual measurement, Wu et al. [16] obtained the basic characteristics and laws of deformation and failure of mined out roadway in steeply inclined critical angle coal seam through actual measurement and proposed that the main feature of deformation and failure of mining roadway in steeply inclined critical angle coal seam is asymmetric deformation. The mechanism of asymmetric failure and serious deformation failure of large dip critical angle coal seam is revealed. It is considered that for the roadway with asymmetric deformation, the corresponding section form must be adopted to ensure the stability of roadway surrounding rock and reduce the support cost.

The mining succession of Qidong mine is relatively tight. In order to reduce the amount of roadway excavation, improve the roadway maintenance conditions and improve the economic and technical conditions of mine safety production, the key technology of Retaining Roadway along goaf with hard roof is studied. Through this research, a set of gob-side entry retaining technology system suitable for the mining area is formed, so that the excavation quantities of one mining roadway near the replacement face can be reduced, and the tension of mining replacement can be effectively alleviated. It can improve the maintenance conditions of high stress roadway along goaf with large mining depth and reduce the roadway maintenance cost. It can also help realization of continuous mining without coal pillar, reduce the loss of coal resources, improve the recovery rate of mining area, increase the recoverable reserves of the mine, and prolong the service life of the mine.

\section{Mining and Geological Conditions for the Case Study of Coal Mine}

Qidong Coal Mine is located in Suzhou City, Anhui Province, China, with an approved production capacity of 1.8 million $\mathrm{t} / a$, mainly mining $6_{1}, 7_{1}, 8_{2}$, and 9 \# coal. If two roadways are arranged in one working face in the past, the following problems may be faced: (1) One working face is arranged with two parallel grooves, the roadway excavation speed is slow, the overall excavation rate is high, and the excavation cost is high, which is easy to cause the tense situation of mine excavation replacement. (2) $6 \mathrm{~m}$ coal pillar is reserved between two adjacent working faces, resulting in reduced recovery rate of mining area, reduced recoverable reserves of mine, and shortened service life. (3) The reserved size of coal pillar along goaf is not easy to grasp, which often leads to stress concentration and difficult maintenance of adjacent roadway. (4) The side coal pillar in the goaf of the working face is easy to be compressed and even crushed, which is very easy to cause the gas and ponding in the adjacent goaf to flow into the working face, resulting in the gas overrun of the working face and the natural ignition of the residual coal in the goaf, which seriously threatens the safety production of the mine. (5) The working face adopts one-time full-height mining, with large gas emission and easy gas accumulation in the upper corner, which is not conducive to safe and efficient production of the mine. In order to ensure the safe production of 7135 working face, the excavation quantities of adjacent working face roadways and floor extraction roadways are reduced, the excavation cost is reduced, and the tension of working face connection is alleviated; the return air roadway of 7135 working face is reserved along the goaf. It can reduce one roadway in the working face, reduce the loss of coal pillar, and cancel "skip mining." The realization of continuous mining is conducive to the centralization of production: reduce the "two in and one return" Y-type ventilation mode of the working face and eliminate the gas accumulation in the return air corner. Figure 1 shows the view of gob-side entry retaining and stratigraphic column. Figure 2 shows the bolt support drawing of 7135 return air roadway section. The physical and mechanical parameters of each rock stratum are shown in Table 1.

There are many kinds of gob-side entry retaining in China, such as paste-filling gob-side entry retaining, high water-filling gob-side entry retaining, and flexible formwork 


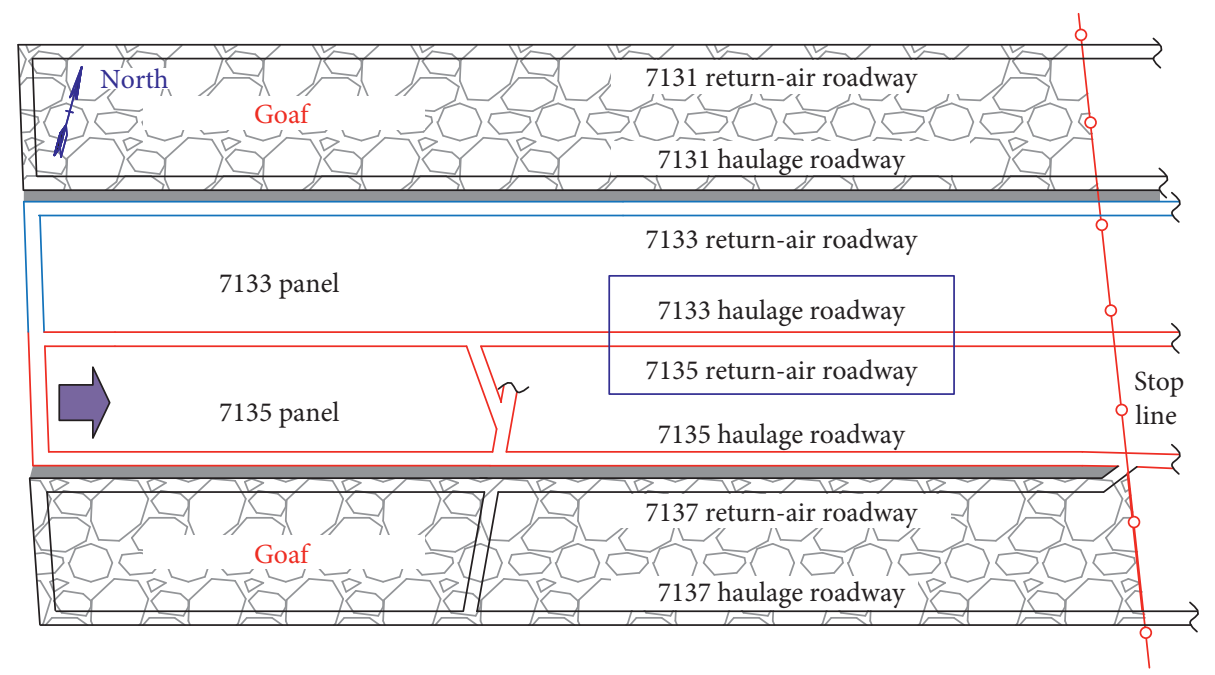

(a)

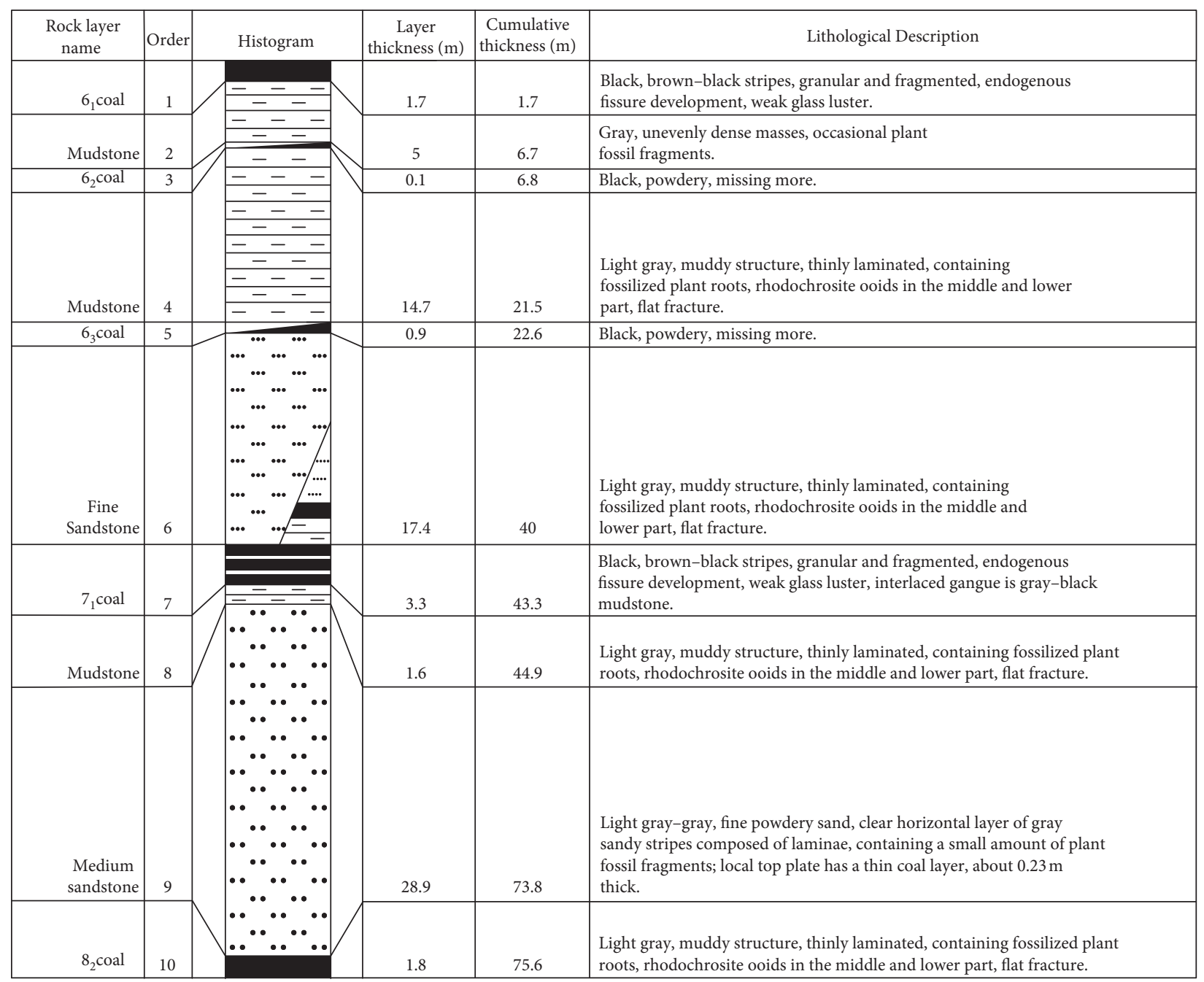

(b)

FIgURE 1: View of gob-side entry retaining and stratigraphic column. (a) View of 7135 full mechanized coal face. (b) Comprehensive stratigraphic column. 
Specification of anchor support: $\phi 20 \times 2400 \mathrm{~mm} \quad$ Specification of anchor support: threaded steel bolt

Rows spacing: $800 \times 800 \mathrm{~mm}$ $\phi 21.6 \times 10300 \mathrm{~mm}$ steel strand

Row spacing: $1500 \times 1600 \mathrm{~mm}$, Walking arrangement

Specification of anchor support: $\phi 20 \times 2400 \mathrm{~mm}$ threaded steel bolt Row spacing $800 \times 800 \mathrm{~mm}$

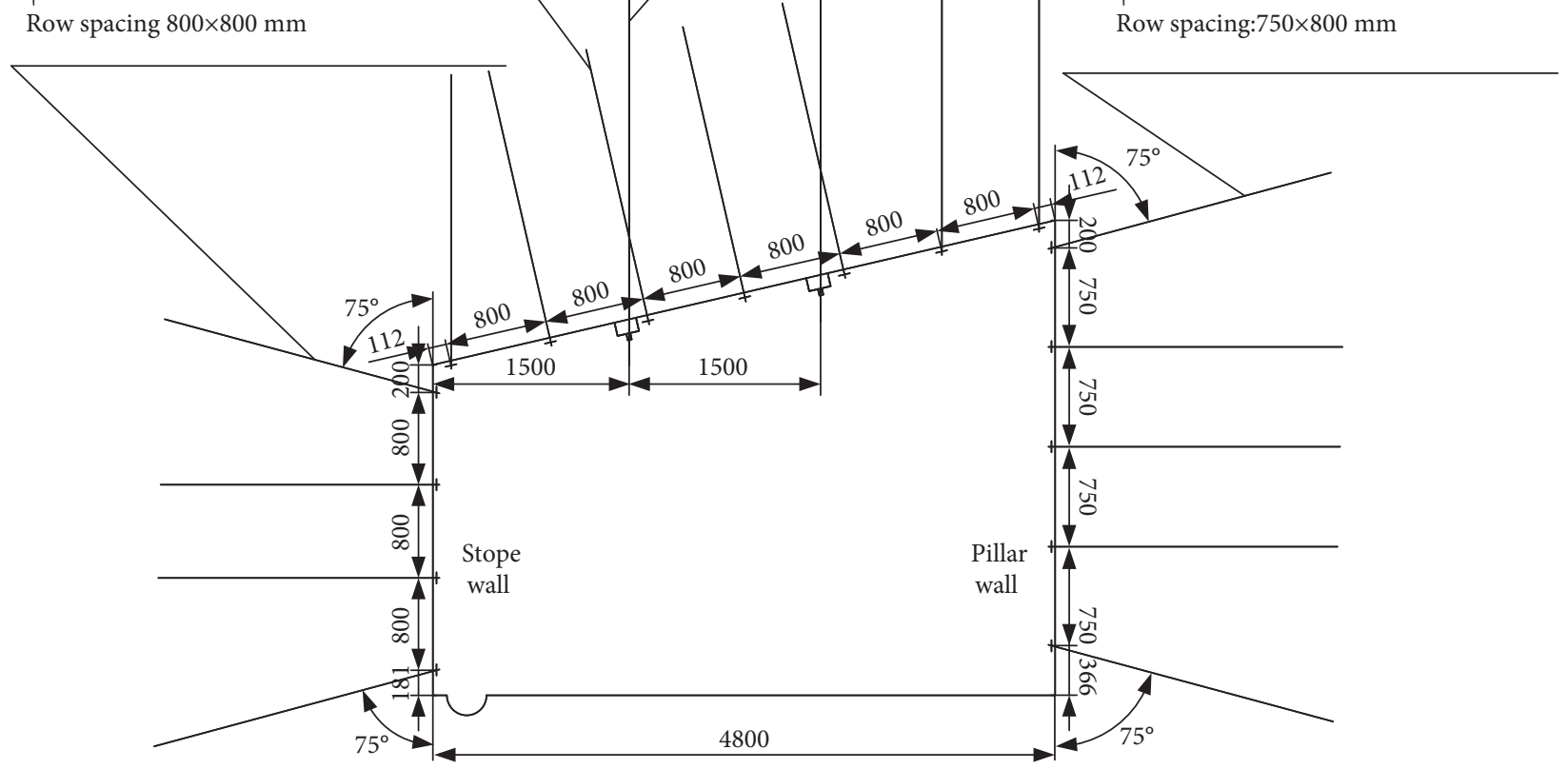

FIGURE 2: Bolt support drawing of 7135 return air roadway section.

TABLE 1: Experimental mechanical parameters of each rock stratum.

\begin{tabular}{|c|c|c|c|c|c|}
\hline Sample name & $\begin{array}{l}\text { Sample } \\
\text { number }\end{array}$ & $\begin{array}{l}\text { Uniaxial compressive strength } \\
(\mathrm{MPa})\end{array}$ & $\begin{array}{l}\text { Uniaxial tensile strength } \\
(\mathrm{MPa})\end{array}$ & $\begin{array}{c}\text { Cohesion } \\
(\mathrm{MPa})\end{array}$ & $\begin{array}{l}\text { Internal friction angle } \\
\left({ }^{\circ}\right)\end{array}$ \\
\hline \multirow{3}{*}{ Main roof } & $1-1-1$ & 65.42 & 5.86 & 7.72 & 45 \\
\hline & $1-1-2$ & 63.45 & 5.96 & 7.86 & 42 \\
\hline & $1-1-3$ & 67.30 & 5.42 & 7.95 & 43 \\
\hline \multirow{3}{*}{$\begin{array}{l}\text { Immediate } \\
\text { roof }\end{array}$} & $2-1-1$ & 33.56 & 4.49 & 2.59 & 40 \\
\hline & $2-1-2$ & 30.21 & 4.51 & 2.46 & 36 \\
\hline & $2-1-3$ & 36.98 & 4.66 & 2.50 & 38 \\
\hline \multirow{3}{*}{ 7\# coal } & $3-1-1$ & 8.45 & 2.19 & 2.09 & 26 \\
\hline & $3-1-2$ & 8.23 & 2.26 & 2.99 & 27 \\
\hline & $3-1-3$ & 8.79 & 2.38 & 2.58 & 29 \\
\hline \multirow{3}{*}{ Floor } & $4-1-1$ & 40.80 & 6.97 & 2.89 & 46 \\
\hline & $4-1-2$ & 45.6 & 6.43 & 2.46 & 48 \\
\hline & $4-1-3$ & 42.5 & 6.82 & 2.99 & 50 \\
\hline
\end{tabular}

concrete-filling gob-side entry retaining. Their common point is the need to form a filling body to support the roadway roof. The process is complex, the equipment investment is large, and the investment is large. The method of roof cutting and pressure relief retaining roadway along the goaf has the advantages of simple system and low cost. Retaining roadway along goaf with roof cutting and pressure relief is a major roadway protection technology conducive to mine safety production and improving mine technical and economic benefits. It can completely cancel the section coal pillar, improve the recovery rate of coal resources, improve the damage condition of roadway surrounding rock, reduce the difficulty of roadway support, reduce the amount of roadway excavation, prolong the service life of min,e and alleviate the contradiction of mining and replacement, canceling isolated island working face, and shortening the moving time of working face can reduce " $Y$ " ventilation and solve the problem of gas overrun in working face.

\section{Application of Deep-Shallow Hole Precracking Blasting Technology}

3.1. Precracking and Blasting Theory of Seam Formation. Based on the above analysis results of the roof collapse and fracture characteristics of the working face and the main factors affecting the stability of the surrounding rock of the gob retaining roadway, the technical principle of roof cutting and pressure relief gob retaining roadway guaranteed by 
cutting off the basic roof is proposed: Before the mining of the working face, the roof cutting technology shall be adopted in the working face where the roadway is planned to be reserved to cut off the basic roof above the roadway and the goaf and the rock stratum below it, so as to avoid the "O$X$ " fracture of the roof above the reserved roadway and reduce the impact of the roof collapse dynamic pressure of the goaf on the reserved roadway (Figure 3). Make the roadway roof form a short arm beam structure and take reinforcement and support measures to strengthen the structure of the short wall beam, improve the overall bearing capacity of the short wall beam, and determine the stability of the reserved roadway roof, as shown in Figure 4(a). After the mining of the working face, the coal gangue support measures shall be taken at one side of the reserved roadway goaf, and the roadway side shall be formed along the coal gangue support measures. The roof is supported by temporary support measures to reduce the impact of surrounding rock dynamic pressure on the reserved roadway, as shown in Figure 4(b). Finally, when the retaining roadway crosses the influence of dynamic pressure, withdraw the temporary support to complete the retaining roadway along the goaf.

\subsection{Numerical Simulation of Precracking Blasting in Hard} Rock Strata. At present, the main numerical simulation methods in the technical field of explosion impact effect are finite difference method, finite volume method, and finite element method. The finite difference method first establishes the differential equations, then covers the time domain and space domain with the help of the grid and uses the difference to replace the differential in the differential equations for approximate numerical solution. The finite difference method is widely used in fluid mechanics and explosion mechanics. The finite element method first decomposes the continuous solution domain into finite elements to form a discrete model and then obtains its approximate numerical solution. Finite element method mainly includes dynamic finite element and structural finite element. Dynamic finite element is mainly used to calculate the strong dynamic load problems with complex boundary shape or including material interface. At present, it has been widely used in the simulation calculation of impact problems. Finite volume method is a kind of numerical method, which transforms partial differential equations into integral form in physical space and then discretizes the conservation law of integral form directly on the selected control volume in physical space.

Because the blasting vibration effect is a nonlinear process, combined with the geological conditions of coal mine, this study uses the finite element analysis software ANSYS/LSDYNA to numerically simulate the changes in effective force between the connecting lines of two adjacent peripheral holes and in the vertical direction during tunnel excavation. The numerical model is mainly composed of explosive, air, and rock. Solid164 solid element is used for finite element simulation, in which explosive and air materials are modeled by Euler grid. The element is practical multimaterial ALE algorithm, and the rock part is modeled by Lagrange grid. Among them, Lagrange and Euler elements are coupled by *CONSTRAINED_LAGRANGE_IN_SOLID function provided by LS-DYNA. Because it is a strip charge, the model can be simplified to a plane symmetry problem without considering the end effect under the condition of center line initiation.

The three-dimensional calculation model is used for simulation. The coordinate axis in the horizontal direction is defined as $X$ axis, the vertical $X$ axis in the horizontal plane is defined as $Y$ axis, and the $Z$ axis is vertically upward. The size of the model is $150 \mathrm{~cm} \times 150 \mathrm{~cm} \times 1 \mathrm{~cm}$. In order to simplify the calculation, the right half region is taken for modeling analysis. Two blast holes are arranged on the model, with a spacing of $50 \mathrm{~cm}$. Uncoupled charge is adopted. The designed blast hole diameter is $5 \mathrm{~cm}$, and the charge roll diameter is $3.5 \mathrm{~cm}$. The established geometric model is shown in Figure 5. Because of the axisymmetric characteristics of the model, 1/2 models are needed to simplify the computation. The whole model is divided into 32193 units, including 1287 explosive units, 1200 air units, and 29706 rock units. According to the above parameters, the calculation model is established. LS-DYNA software can vividly describe the propagation process of stress wave in rock mass medium during blasting. The specific stress wave propagation process is shown in Figure 5. After the explosive is detonated in the blast hole, the stress wave generated takes the blast hole as the center and propagates around with concentric cylindrical wave. The stress wave meets and superimposes at a certain distance between the two blast holes.

\subsection{Precracking Technology for Deep-Shallow Holes in Hard} Rock Strata. For the super thick hard roof slab, deep holes and shallow holes with small spacing and parallel to each other are arranged on the planned seam line. Control the charge quantity of each blast hole, select low-density and low detonation velocity explosives, adopt uncoupled charge structure, and detonate at the same time. The explosive action of the explosive just produces the through crack on the connection line of the blast hole. The deep hole cuts off the deep rock stratum, and the shallow hole cuts off the shallow rock stratum. The scheme is shown in Figure 6. In order to determine the reasonable advance presplitting cutting parameters, the presplitting blasting technology was used to carry out the cutting test in 7135 air roadway. The effect of roof cutting is evaluated by peeping and observing the collapse of the upper corner. Figure 7 shows the drilling arrangement scheme of deep hole and shallow hole blasting and the drilling charging diagram of the two methods. The drilling parameters are shown in Table 2.

The parameters of deep hole charging and hole sealing mainly include the selection of explosives and the structural design of charging and hole sealing. Grade III coal mine allowable emulsion explosive is selected, with diameter of $35 \mathrm{~mm}$, length of $400 \mathrm{~mm}$, and weight of $0.44 \mathrm{~kg}$. According to the coal mine safety regulations, the sealing length of deep 


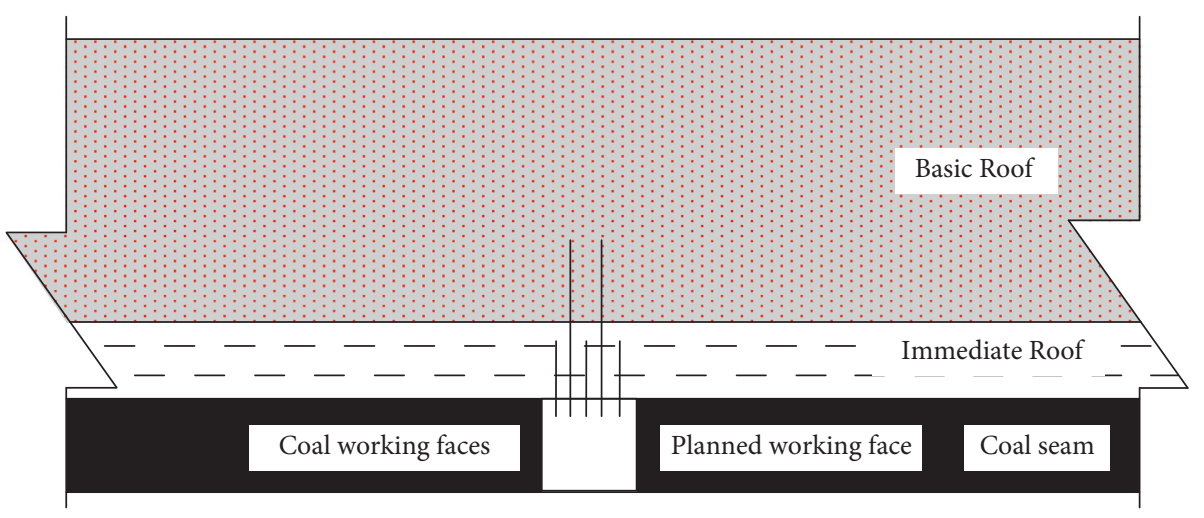

(a)

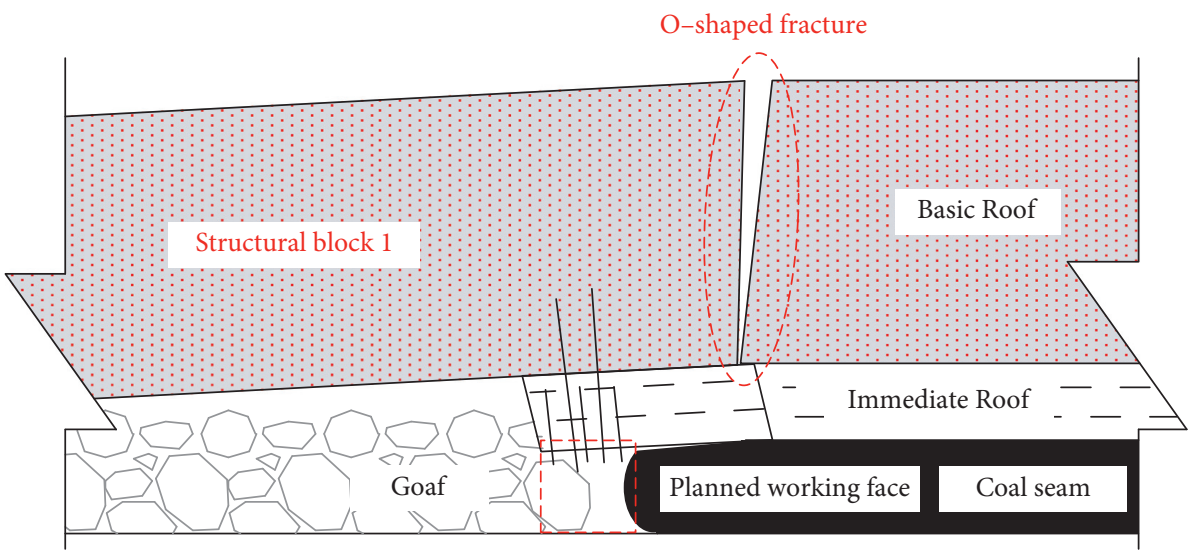

(b)

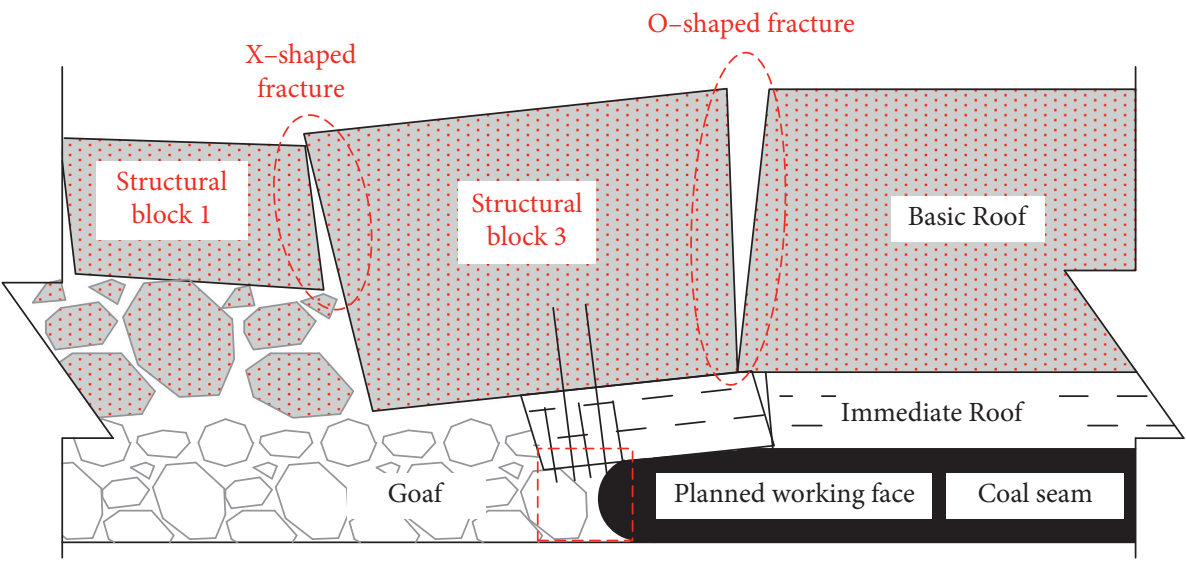

(c)

FiguRE 3: Fracture characteristics of roadway roof. (a) Roof structure before mining in working face. (b) O-shaped fracture of roof after mining. (c) X-shaped roof fracture after mining.

hole blasting shall not be less than one third of the hole depth. The sealing length is $6 \mathrm{~m}$, which is greater than one third of the blast hole depth, i.e., $5.9 \mathrm{~m}$, meeting the requirements. Therefore, the length of charging section is $11.4 \mathrm{~m}$. The charging section is $11.4 \mathrm{~m}, \mathrm{PE}$ half pipe (double antistatic, flame retardant, and antistatic) is used as the carrier, and the explosives are bound on the half pipe with adhesive tape and sent to the blast hole. The inner diameter of PVE half pipe is $32 \mathrm{~mm}$, the outer diameter is $36 \mathrm{~mm}$, and the length of each section is $2 \mathrm{~m}$. The half pipe is connected with the inner wire and outer wire joints through the inner wire and outer wire joints. The charging section is divided into upper and lower parts. The upper part is charged with 15 rolls, which are continuously and seamlessly arranged close to the edge of $\mathrm{PE}$ half pipe, the lower part is 12 rolls, which are evenly spaced, and there are 2 sections of water blasting mud. The hole sealing section shall not be less than $6 \mathrm{~m}$, and water cannon mud and clay cannon mud shall be used for hole sealing. There are 2 pieces of water gun mud, with a total length of $0.5 \mathrm{~m}$ and clay gun mud of $6 \mathrm{~m}$. The explosive is 


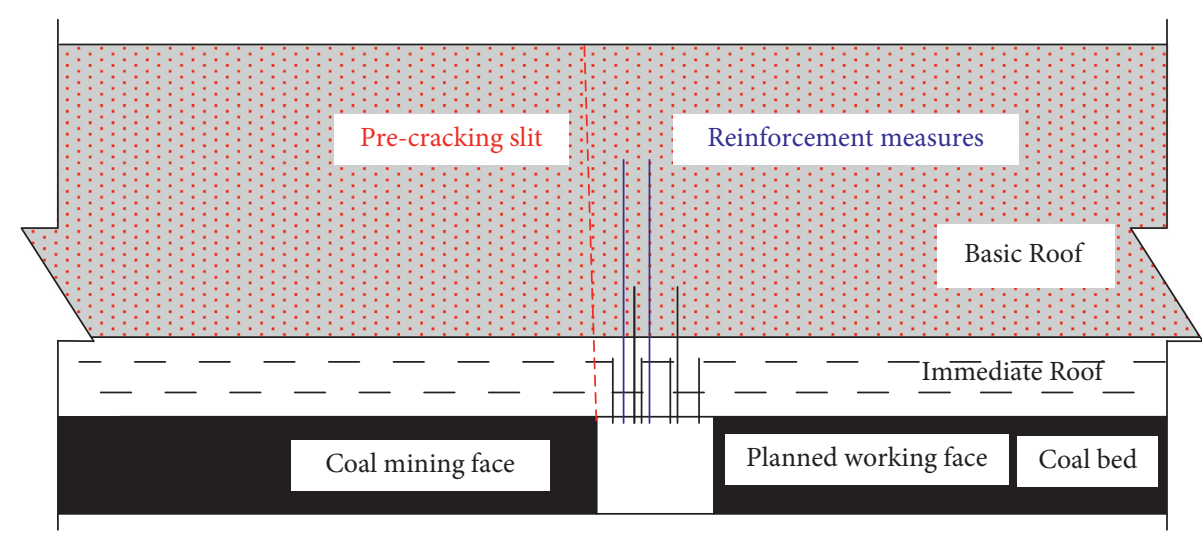

(a)

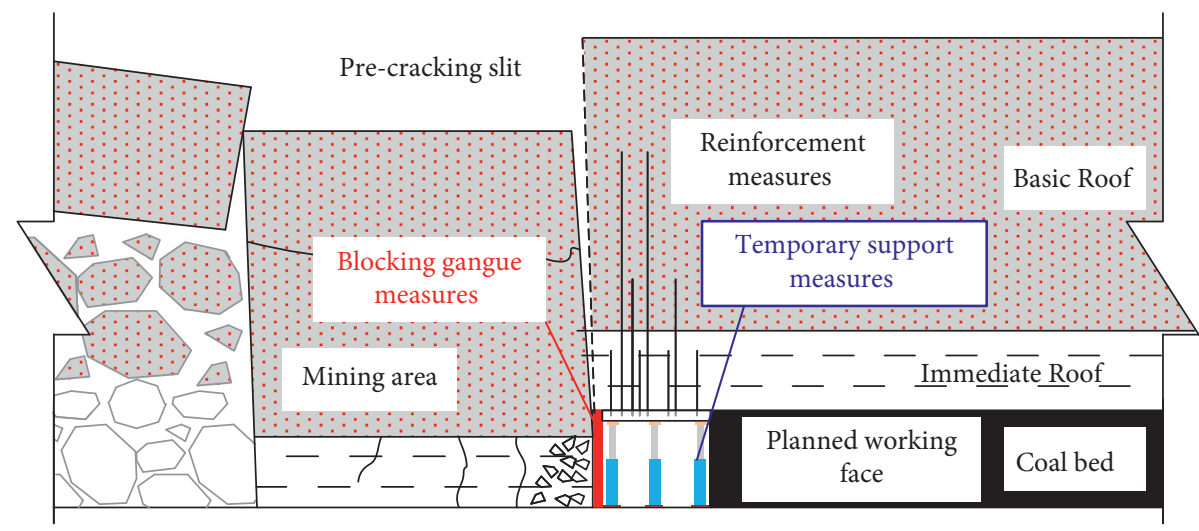

(b)

FIGURE 4: Technical principle of roof cutting and pressure relief retaining roadway along goaf. (a) Roof cutting and reinforcement support shall be carried out before mining. (b) Gangue retaining and temporary support after mining.

detonated by electric detonator and transmitted by detonating cord. The electric detonator charges in the forward direction, and 2 millisecond electric detonators are generated for each borehole. Parallel arrangement inside the hole and series arrangement outside the hole. No more than 15 boreholes shall be blasted at one time.

Shallow hole blasting is to cut the top of deep hole sealing section, so its drilling parameters are the same as those of deep hole except depth. That is, the distance between the borehole and the stope is $200 \mathrm{~mm}$, and the dip angle is $80^{\circ}$, diameter is $50 \mathrm{~mm}$, and drilling spacing is $600 \mathrm{~mm}$, arranged at intervals from deep holes. The length of deep hole sealing is $6 \mathrm{~m}$, so the depth of shallow hole is $6 \mathrm{~m}$. The length of hole sealing is $2 \mathrm{~m}$, and the length of charging section is $6-2=4 \mathrm{~m}$. The charging section is $4 \mathrm{~m}$, PE half pipe (double antistatic, flame retardant, and antistatic) is used as the carrier, and the explosives are bound on the half pipe with adhesive tape and sent to the blast hole. The charging section is divided into upper and lower parts. The upper part is charged with 4 rolls, which are continuously and seamlessly arranged close to the edge of PE half pipe, the lower part is charged with 2 rolls, which are continuously and seamlessly arranged, and there are 2 sections of water cannon mud. The hole sealing section shall not be less than $2 \mathrm{~m}$, and the hole shall be sealed with water gun mud and clay gun mud. The total length of water gun mud is $0.5 \mathrm{~m}$, and the length of clay gun mud is $2 \mathrm{~m}$. The explosive shall be detonated by electric detonator and transmitted by detonating cord. The electric detonator shall be charged in the forward direction. Two millisecond electric detonators shall be fired in each borehole. They shall be arranged in parallel in the borehole and in series outside the borehole. No more than 10 boreholes shall be blasted at one time.

3.4. Observation Results and Effect Evaluation of Roof Cutting. The effect of blasting seam cutting is affected by many factors, and its quality is mainly evaluated from the following two aspects: (1) peeping before and after blasting in the borehole, through peeping before and after blasting in the borehole, the blasting seam cutting effect is compared and analyzed. If there is no obvious development of rock cracks in the borehole after blasting, the blasting seam cutting parameters need to be optimized. (2) Additional peeping holes shall be drilled after blasting, after blasting of adjacent holes, additional peeping holes shall be drilled in the middle of the connecting line between the two holes to observe the development of rock fractures in the holes. If the rock fractures are developed in the direction of the connecting line of blasting holes, it indicates that the joint forming effect is good; otherwise, the advance precrack cutting parameters shall be optimized. 


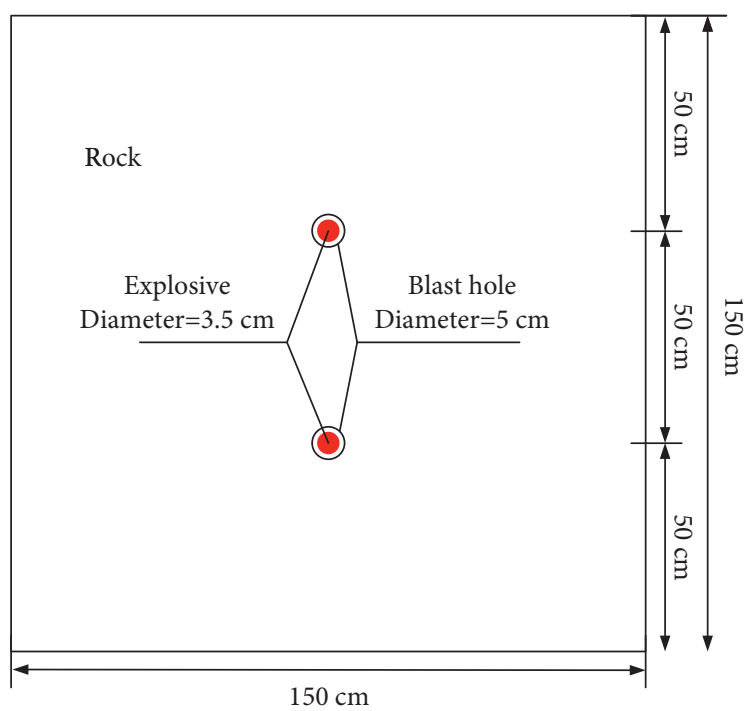

(a)

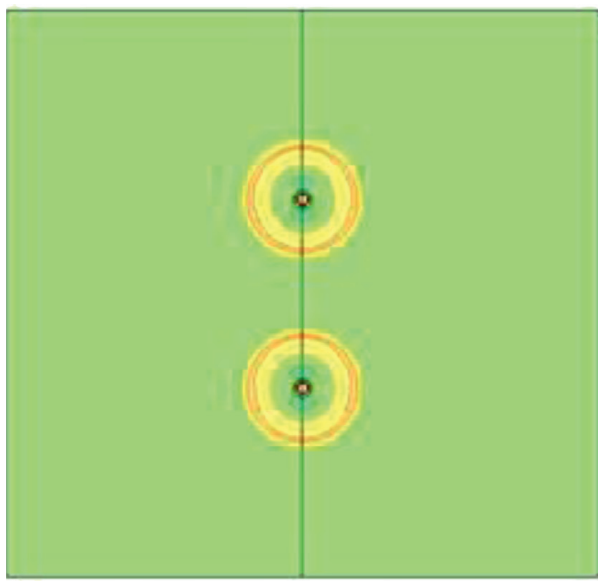

(c)

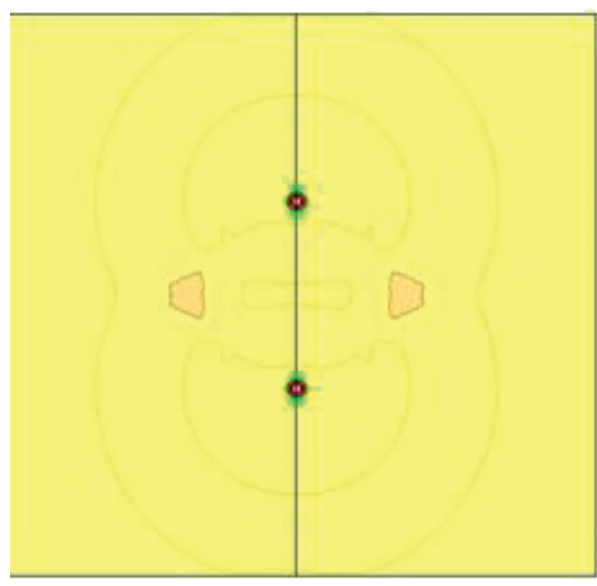

(e)
Fringe Levels

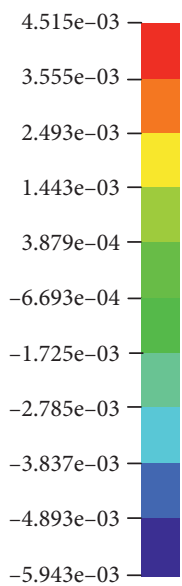

$-5.943 \mathrm{e}-03$

Fringe Levels

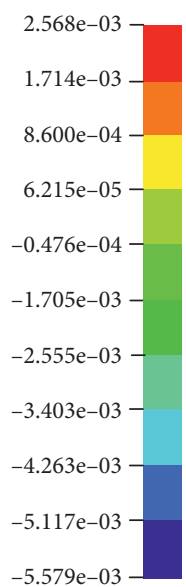

$-5.579 \mathrm{e}-03$
Fringe Levels
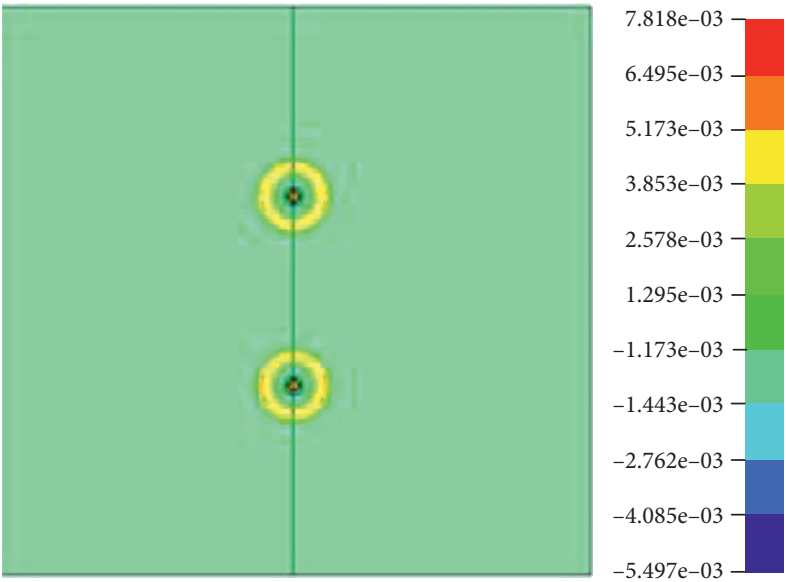

(b)

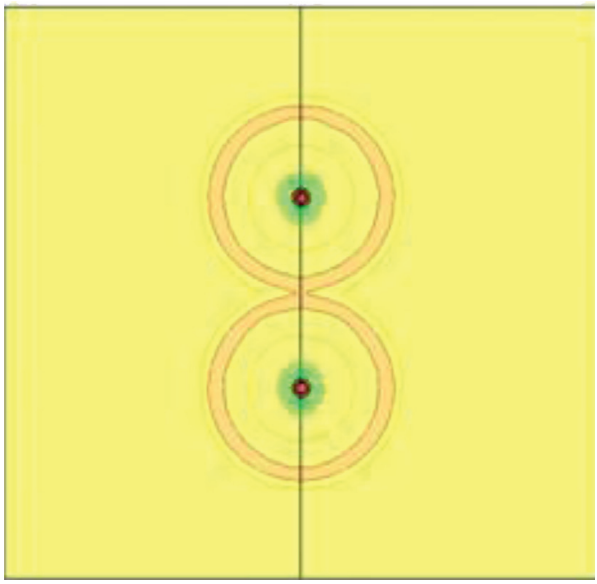

(d)

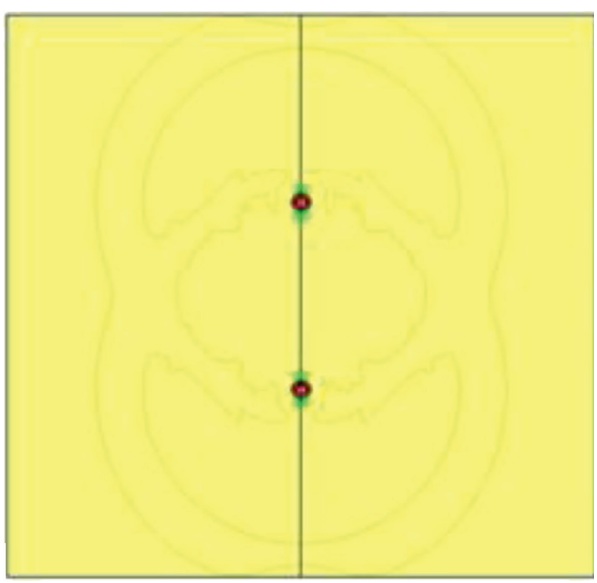

Fringe Levels

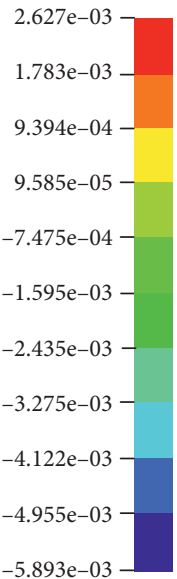

(f)

FIGURE 5: Construction of presplitting blasting model and evolution process of stress wave state. (a) Geometric model of presplitting blasting simulation. (b) $\mathrm{T}=25 \mu \mathrm{s}$. (c) $\mathrm{T}=40 \mu \mathrm{s}$. (d) $\mathrm{T}=60 \mu \mathrm{s}$. (e) $\mathrm{T}=113 \mu \mathrm{s}$. (f) $\mathrm{T}=133 \mu \mathrm{s}$. 


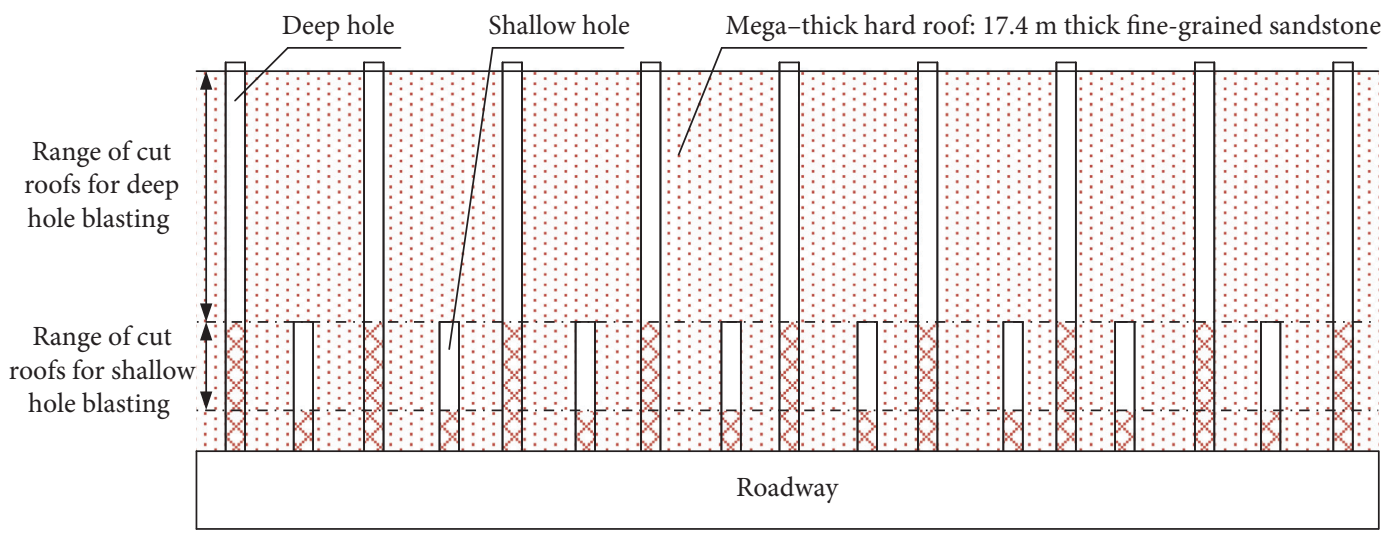

Figure 6: Deep-shallow hole blasting scheme.

In order to test the effect of blasting slit cutting, it is necessary to peep at the blasting borehole. The specific scheme is as follows: ZKXG-30 mining borehole imaging trajectory detection device is used to peep before and after blasting. After drilling and blasting, additional peeping holes shall be drilled between the two blasting holes. The parameters of additional drilling holes shall be the same as those of blasting holes and must be located in the middle of the connecting line between the two blasting holes. If the crack propagation length along the top cutting line in the blast hole exceeds $50 \%$ of the drilling depth, and there are obvious cracks on the connecting line of adjacent blast holes, it indicates that the crack formation effect is good. Otherwise, the design of advance presplitting cutting joint shall be optimized and observed again until the observation results meet the technical requirements of roof cutting and pressure relief roadway retention along the goaf.

By adjusting the parameters of single hole charging and hole sealing, the drilling peep is used to detect the blasting effect on site (see Figure 8). The peeping results show that during deep hole blasting, the crack forming rate in the charging section exceeds $85 \%$, and the blasting crack forming effect is good. In shallow hole blasting, the crack forming rate in the charging section exceeds $90 \%$, and the blasting crack forming effect is good. The deep hole and shallow hole are combined for evaluation. The drilling depth is $17.8 \mathrm{~m}$, and the joint length is more than $15.4 \mathrm{~m}$. Symmetrical cracks are obvious, and the crack forming rate is $87 \%$, indicating that presplitting blasting can form directional cracks in the roof and form structural weak planes, which is conducive to roof fracture and achieve the purpose of presplitting blasting.

\section{The Method of Controlling the Surrounding Rock of Gob-Side Entry Retaining with Hard Roof}

4.1. The Technology of Blocking Gangue along the Gob-Side Entry Retaining. High-strength prestressed anchor cable reinforcement support is added on the basis of the original support, and the specification of anchor cable is $21.6 \times 12300 / 10300 \mathrm{~mm}$. The anchoring end shall enter at least $1.0 \mathrm{~m}$ above the basic top fine sandstone to ensure the effectiveness of anchoring. One reinforced support anchor cable shall be arranged in each row along the vertical direction. The row spacing is $800 \mathrm{~mm}$, the anchor cable is $600 \mathrm{~mm}$ from the mining side and $4200 \mathrm{~mm}$ from the coal pillar side. Four rolls of resin cartridge are used for lengthening anchorage, with two rolls of $\mathrm{k}-2370$ resin cartridge at the upper part and two rolls of $\mathrm{z}-2370$ resin cartridge at the lower part, as shown in Figure 9.

Within the lagging temporary support area behind the working face, the lagging temporary support scheme of $\pi$ beam shed is composed of " $\pi$ beam and single hydraulic prop." The top beam is a $1.2 \mathrm{~m}$ long $\pi$ beam, which is arranged along the roadway trend, with a distance of $1100 \mathrm{~mm}$. "One beam and two columns "are arranged, and the initial support force of all single hydraulic pillars is not less than $100 \mathrm{kN}$. The design of lag temporary support scheme is shown in Figure 10.

4.2. Ground Pressure Behavior Characteristics of Gob-Side Entry Retaining with Hard Roof. The support systems such as roadway surface displacement, anchor cable load, roof separation, and support working resistance of transportation roadway are monitored, and the monitoring data are sorted and analyzed. The purposes are as follows: (1) to master the dynamics and laws of roadway surrounding rock, so as to provide scientific basis for daily dynamic management of roadway support; (2) provide scientific basis for testing the rationality of support structure, design parameters and construction technology, and modifying and optimizing support parameters; (3) monitor the construction quality, track, feed back, and predict the support status, and timely find out the hidden dangers of the project, so as to ensure the construction safety and roadway stability; (4) provide a comprehensive reference for the design and construction of other similar projects; and (5) the monitoring data can be used as the standard for judging the quality inspection and acceptance of roadway engineering.

After adopting the technology of roof cutting and pressure relief, the deformation and stress of roadway and working face need to be monitored in order to formulate further measures. One measuring station is arranged every 


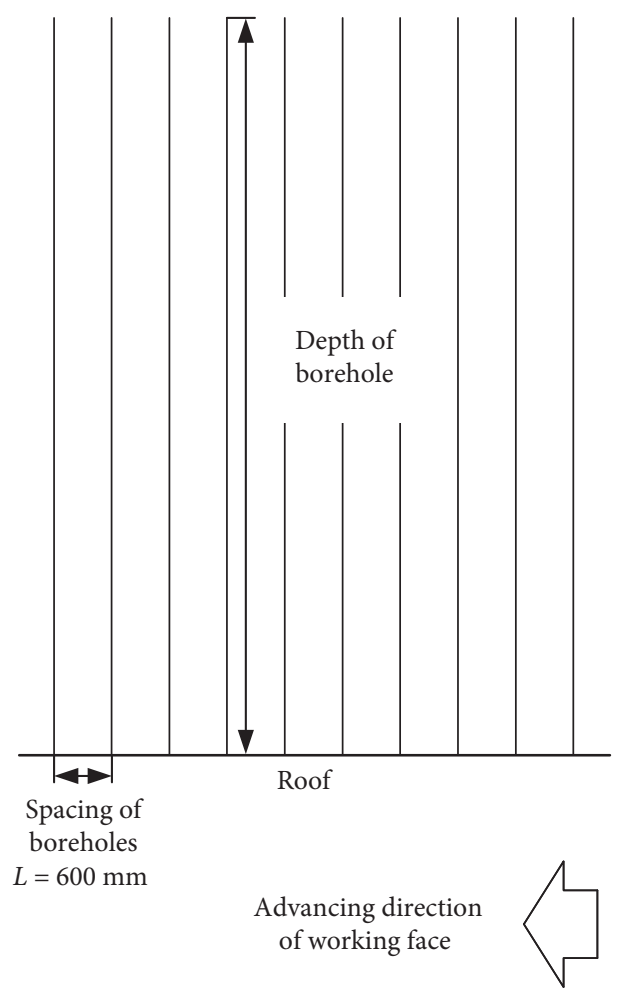

Floor

(a)

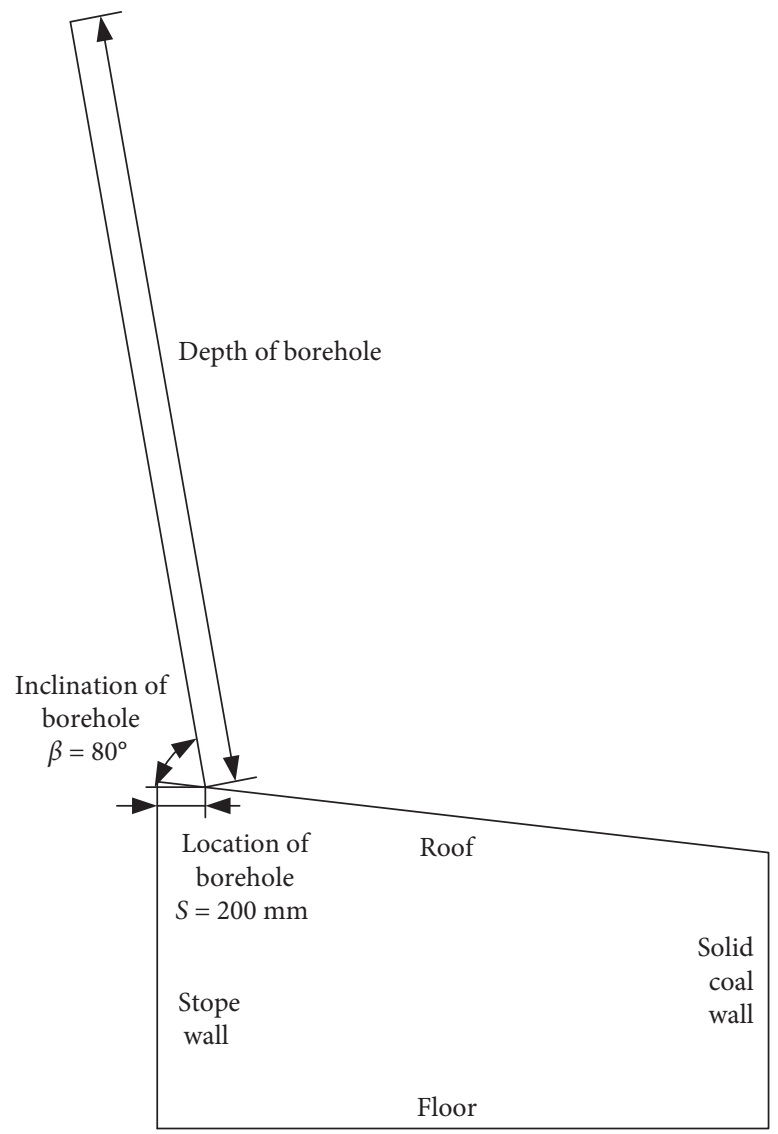

(b)

Figure 7: Continued. 


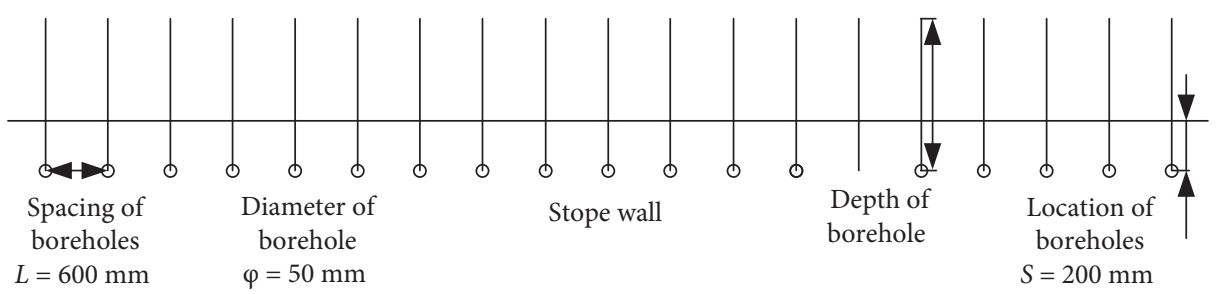

Solid coal wall

(c)

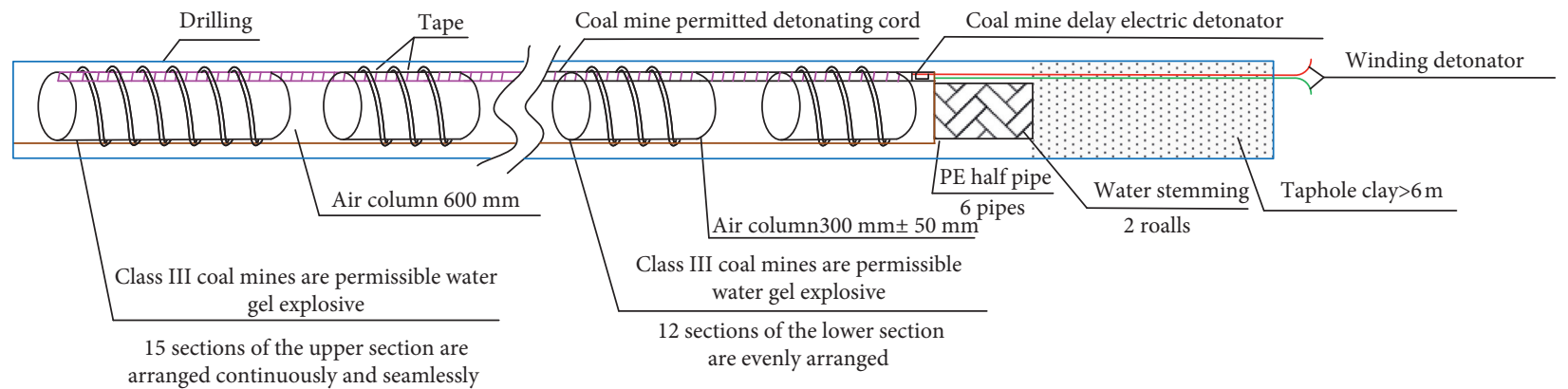

(d)

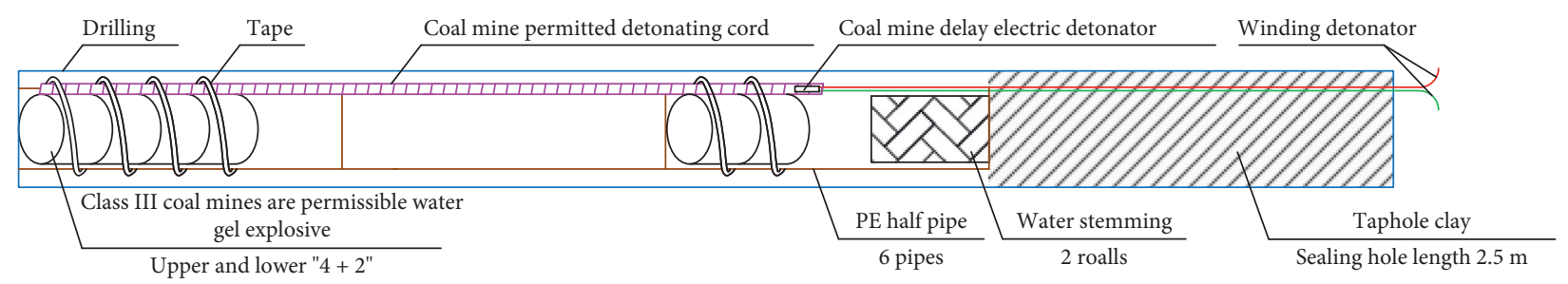

(e)

Figure 7: Scheme of deep hole and shallow hole blasting. (a) Front view. (b) Side view. (c) Vertical view. (d) Schematic diagram of charging explosives for deep hole blasting. (e) Schematic diagram of charging explosives for shallow hole blasting.

TABLE 2: Parameters of blasting presplitting roof.

\begin{tabular}{lcc}
\hline Design parameters & Peep hole blasting & Sarameter value \\
\hline Distance from borehole to stope & $200 \mathrm{~mm}$ & $200 \mathrm{~mm}$ \\
Direction of drilling & Vertical to the center line of the roadway and inclined to the stope \\
Inclination of borehole & $80^{\circ}$ & $80^{\circ}$ \\
Depth of borehole & $17800 \mathrm{~mm}$ & $6000 \mathrm{~mm}$ \\
Diameter of borehole & $50 \mathrm{~mm}$ & $50 \mathrm{~mm}$ \\
Spacing of boreholes & $600 \mathrm{~mm}$ & $600 \mathrm{~mm}$ \\
\hline
\end{tabular}

$20 \mathrm{~m}$ within $100 \mathrm{~m}$ of 7135 return air roadway from the cutting hole, and one measuring station every $100 \mathrm{~m}$ after $100 \mathrm{~m}$. The layout of the survey station is shown in Figure 11. By analyzing the data during the observation period, it is found that when the 7135 working face is pushed about $400 \mathrm{~mm}$, the deformation of both sides of the roadway and the roof is close to stability. The approach of the two sides is 90-510 $\mathrm{mm}$, with an average of $130 \mathrm{~mm}$, and the roof subsidence is $45-500 \mathrm{~mm}$, with an average of $140 \mathrm{~mm}$.

The variation curve of roof separation layer is shown in Figure 12. The shallow base point of the ionometer is $2.5 \mathrm{~m}$, and the deep base point is $10 \mathrm{~m}$, which is the same as the anchorage position of the anchor cable. In the figure, the shallow separation refers to the separation amount of rock strata below $2.5 \mathrm{~m}$, the deep separation refers to the separation amount of rock strata between 2.5 and $10 \mathrm{~m}$, and the full-length separation amount refers to the separation amount of all rock strata between 0 and $10 \mathrm{~m}$ of the roof. It can be seen from Figure 12 that before the dynamic pressure of the working face comes, the roof is generally in a very stable state. The shallow separation is $2 \mathrm{~mm}$, the deep separation is $1 \mathrm{~mm}$, and the total separation is $3 \mathrm{~mm}$. When the working face is pushed forward, the roof appears obvious layer under the influence of advance bearing pressure, and 

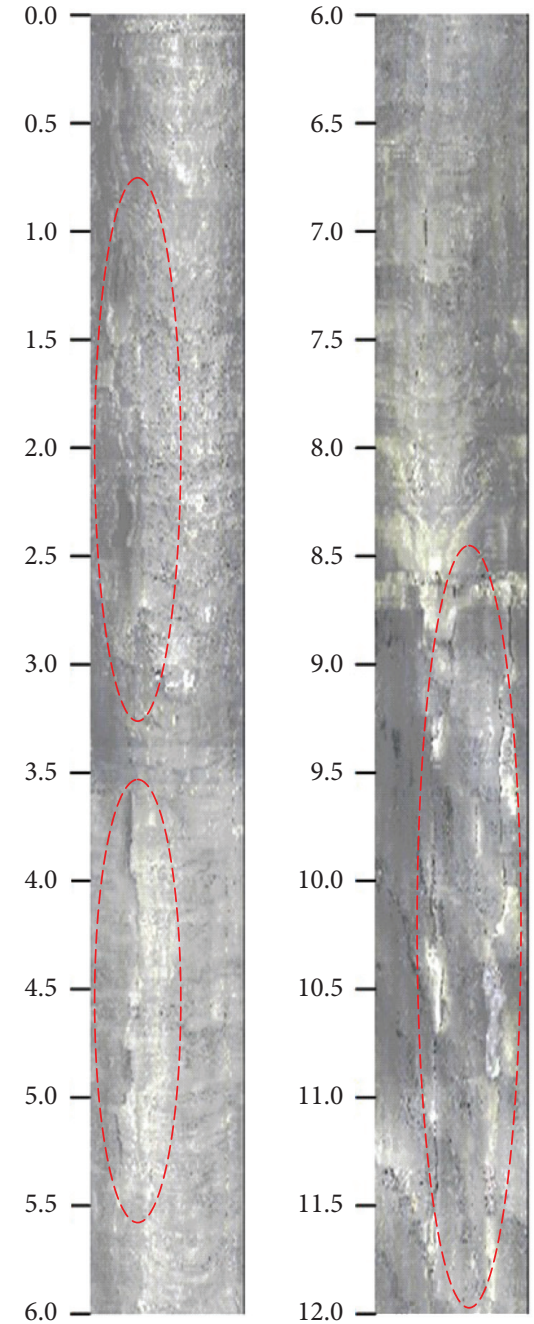

(a)
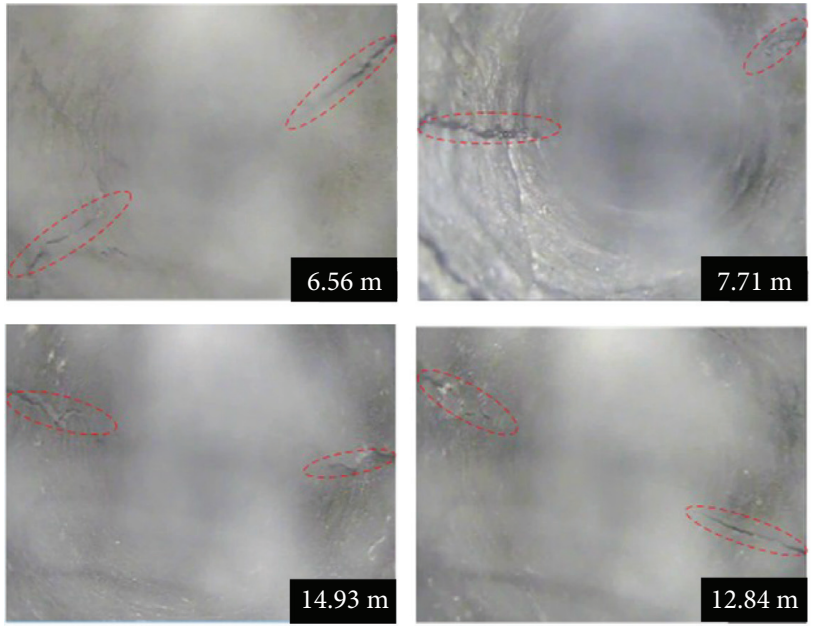

(c)
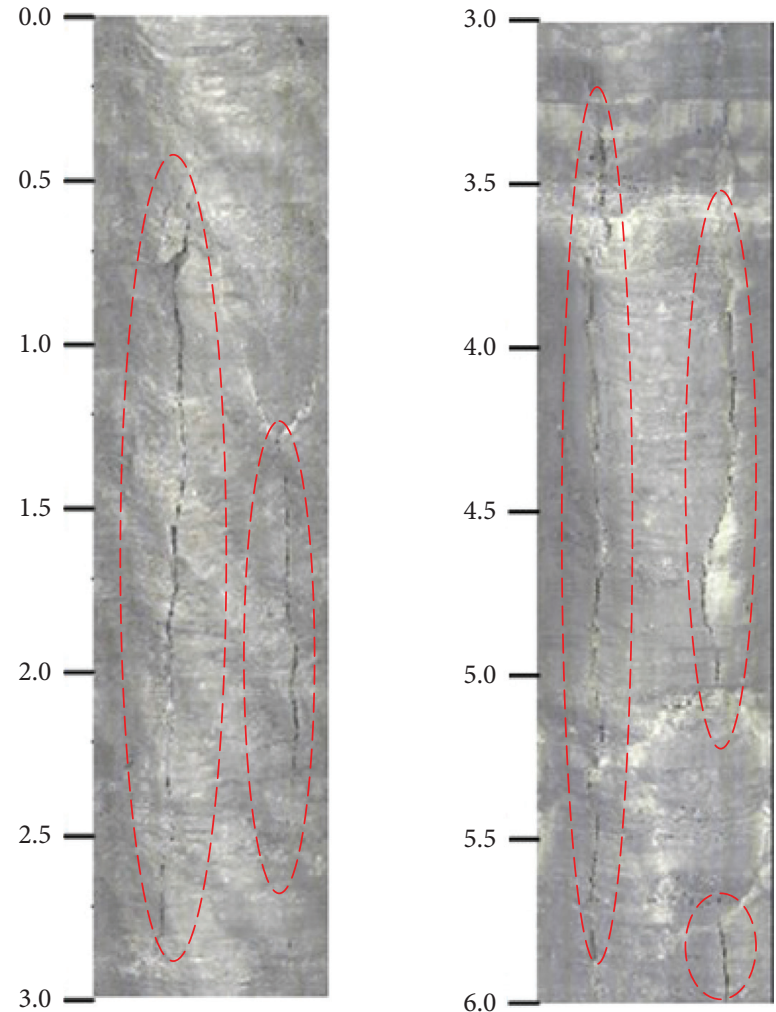

(b)
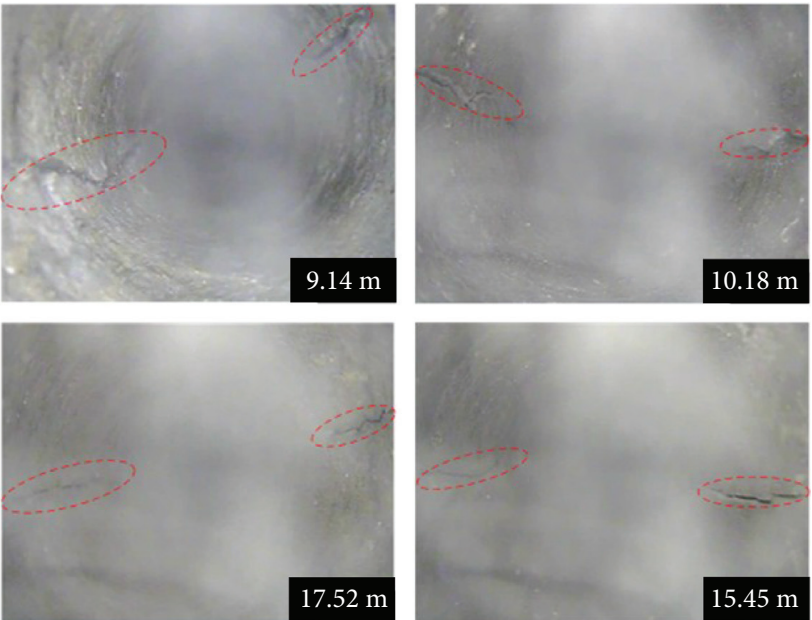

Figure 8: Test of roof cutting effect of presplitting blasting based on borehole peeping method. (a) Peeping results of typical deep hole presplitting blasting. (b) Peeping results of shallow hole blasting. (c) Symmetric fracture formation in a typical hole. 


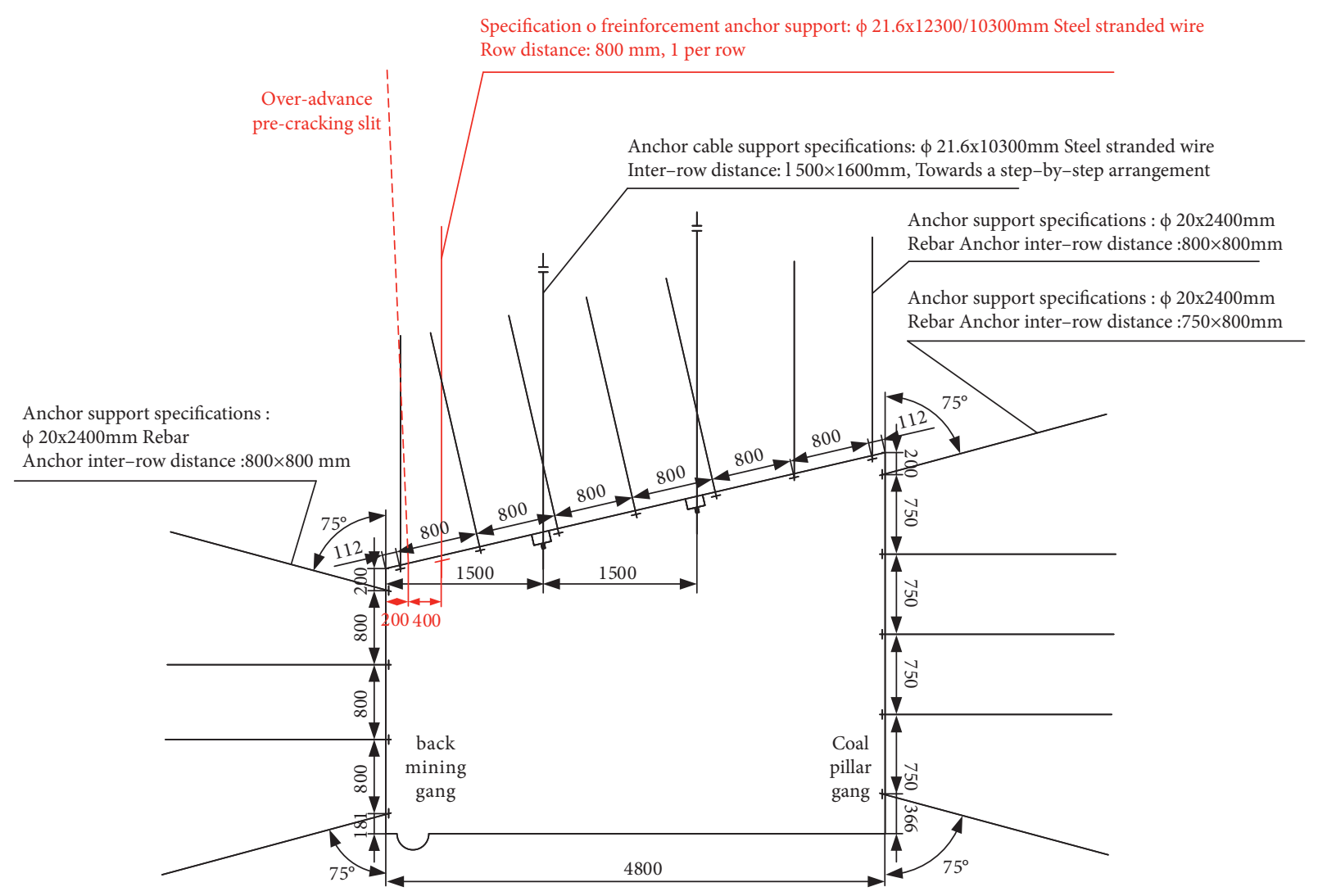

(a)

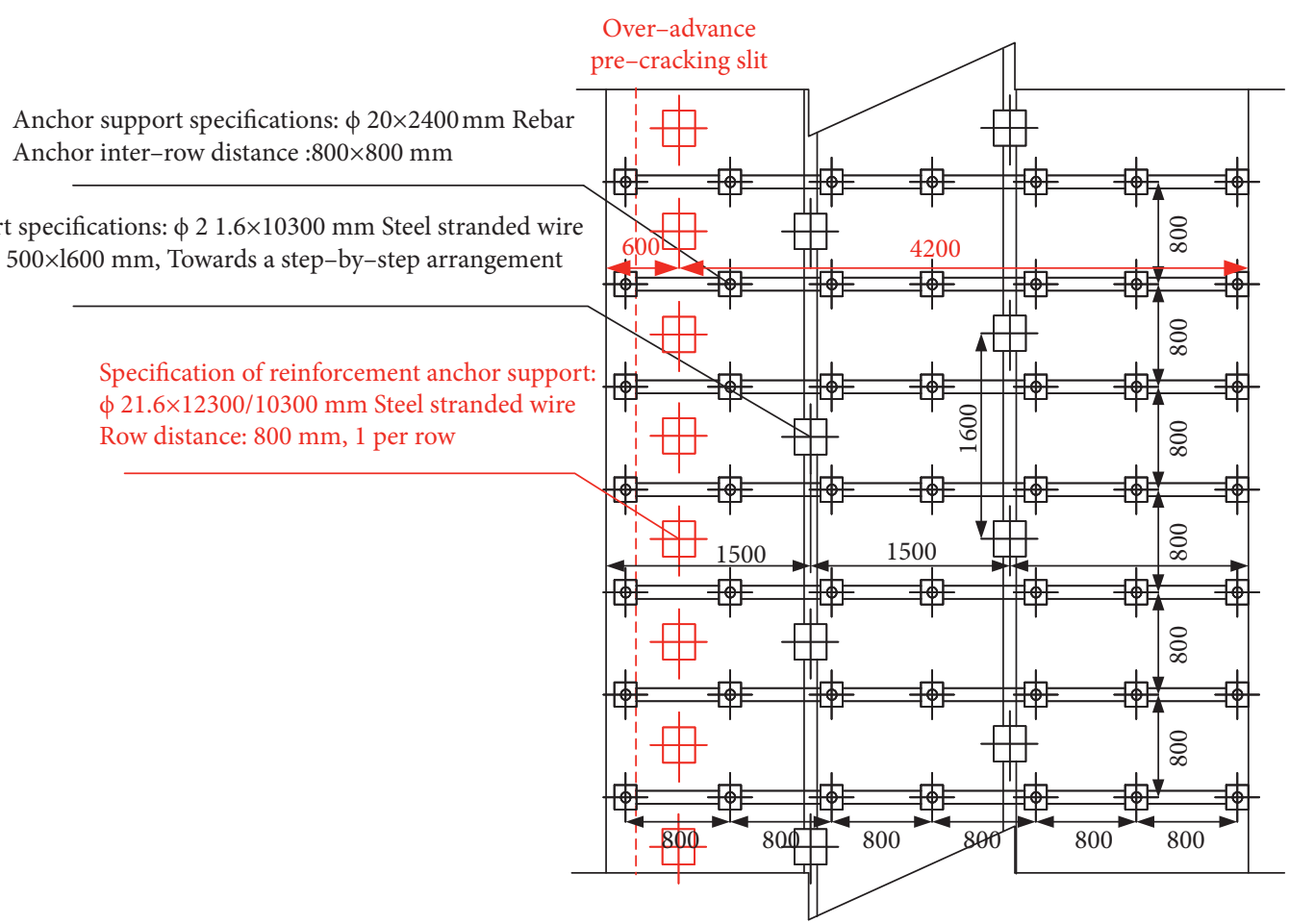

(b)

Figure 9: Section and plan of roof reinforcement and support. 


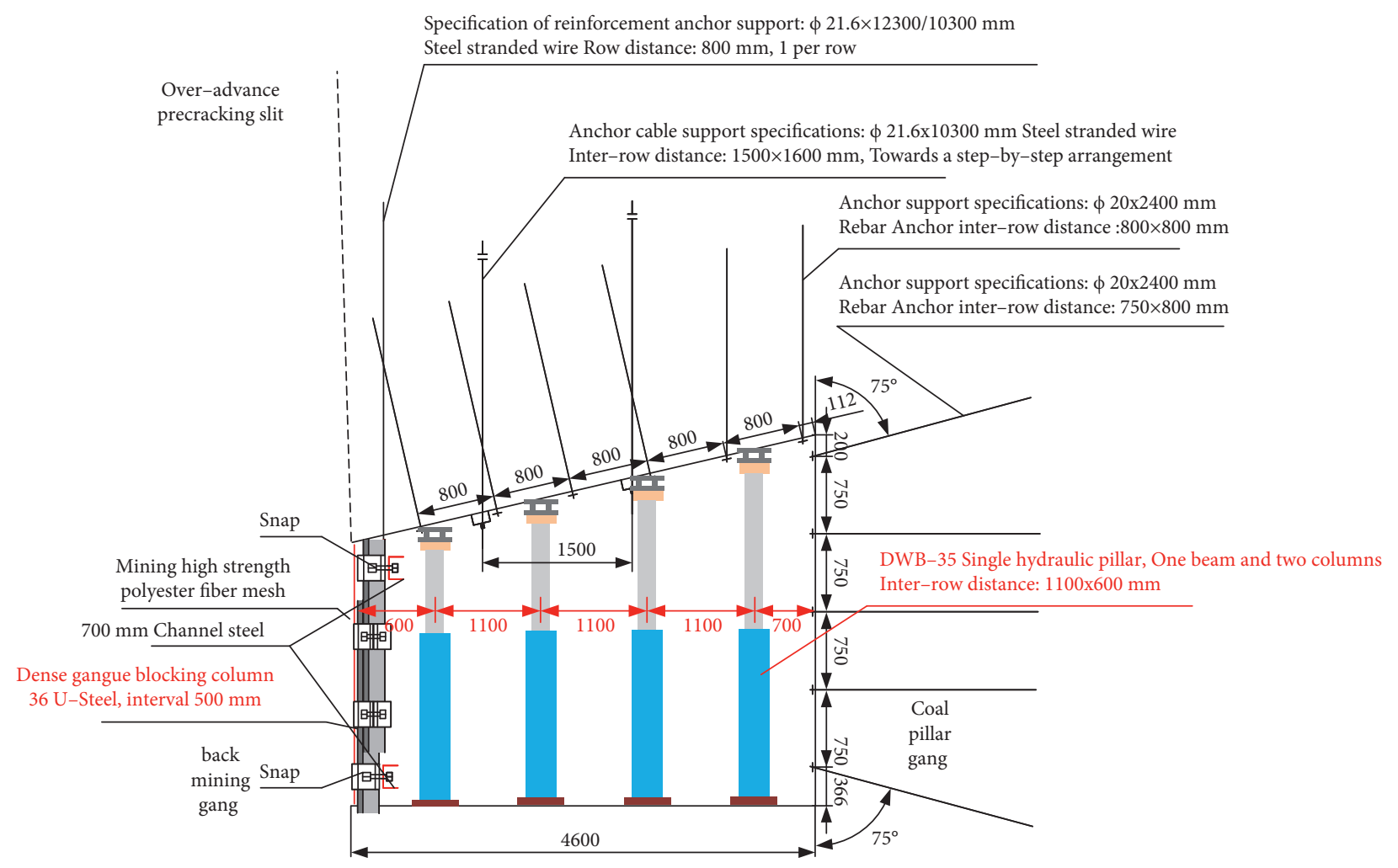

(a)

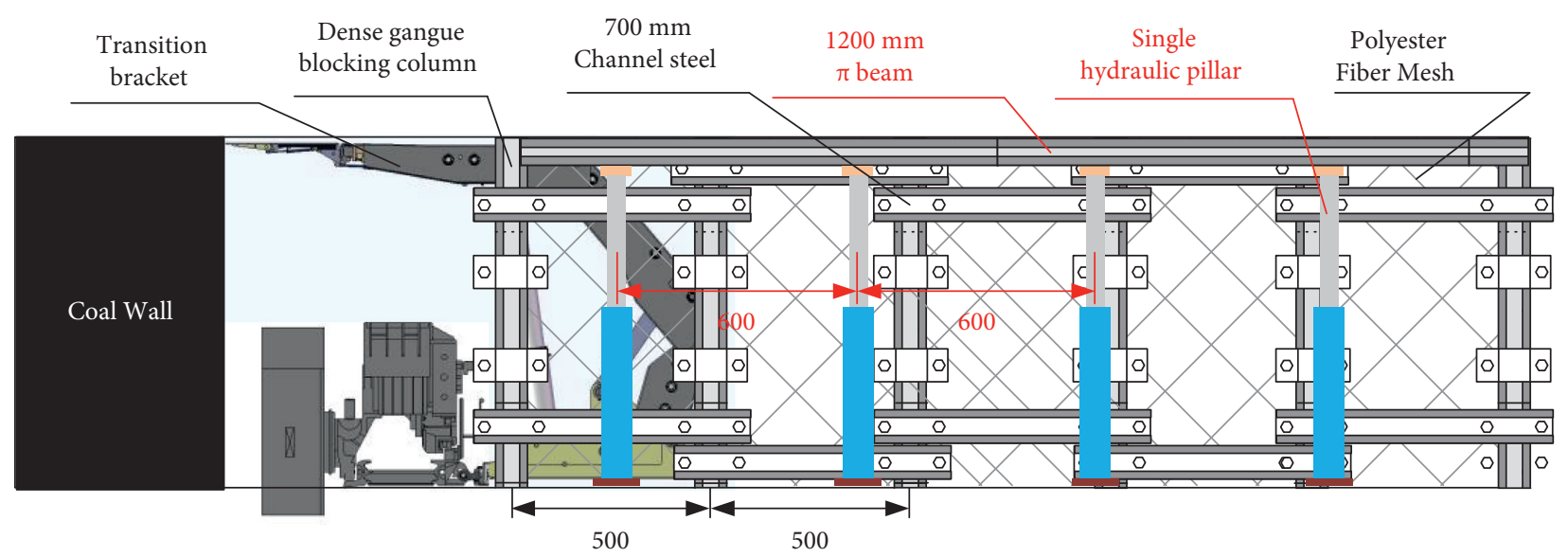

(b)

Figure 10: Section and side view of lagging temporary support.

the layer separation increases rapidly. The shallow, deep, and full-length separation increases to $11 \mathrm{~mm}, 21 \mathrm{~mm}$, and $32 \mathrm{~mm}$, respectively. The increase in deep separation is about twice that of shallow separation. At $10 \mathrm{~m}$ after the working face is pushed forward, the variation of roof separation gradually decreases, and at $30 \mathrm{~m}$ behind the working face, the roof separation gradually stabilizes. The total accumulated layer separation is $32 \mathrm{~mm}$, indicating that the roadway support is in good condition, and the roof is stable. Figure 13 shows the site photographs of the implementation of surrounding rock control technology for retaining roadway along goaf. The roadway after presplitting blasting and strengthened support can be seen that the roadway support is in good condition and the roof is stable. 


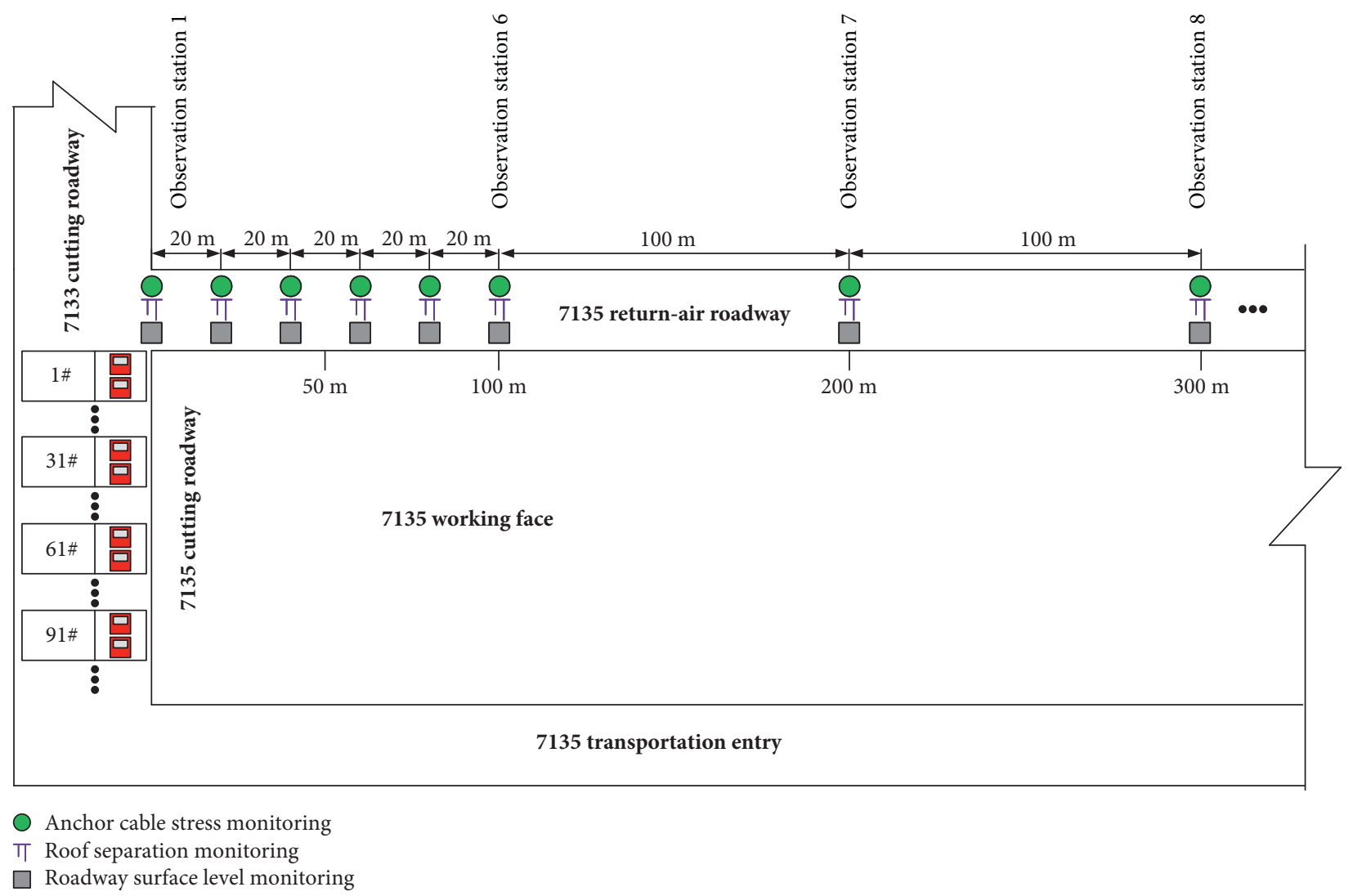

FIGURE 11: Setting of ground pressure observation station.

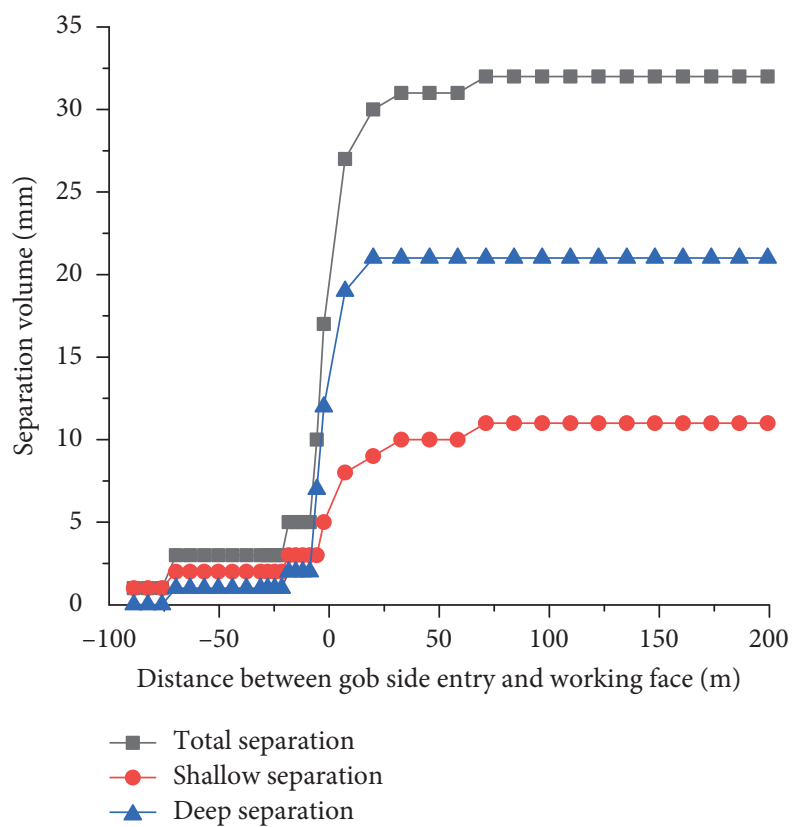

FIGURE 12: The roof separation instrument records the roof separation change curve at $200 \mathrm{~mm}$ of the return air roadway. 


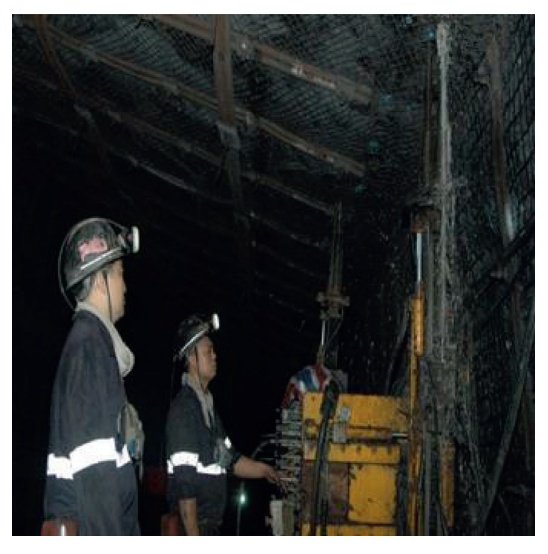

(a)

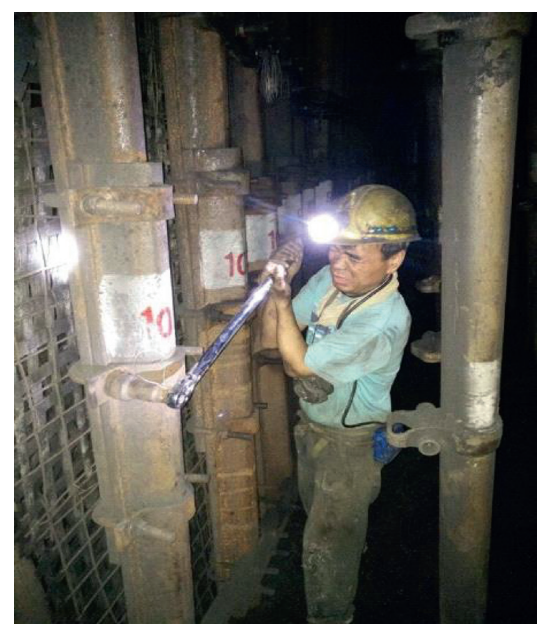

(d)

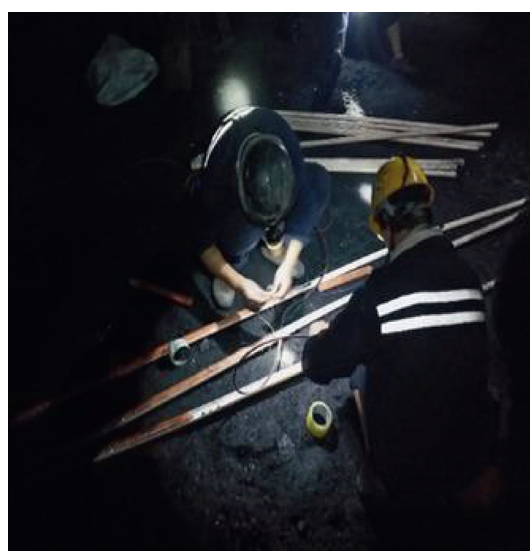

(b)

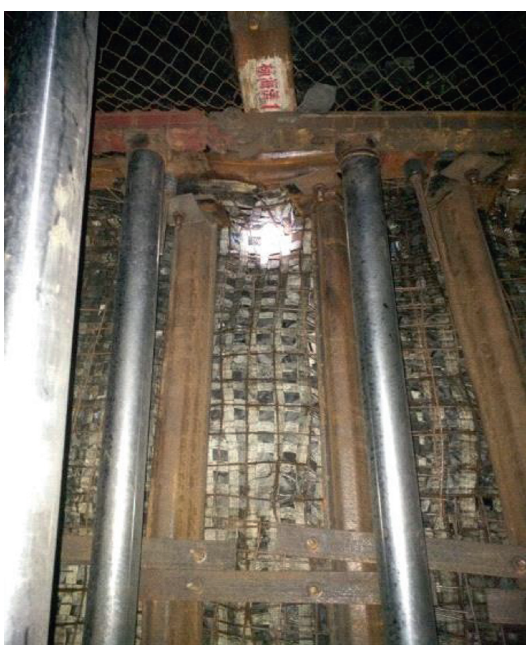

(e)

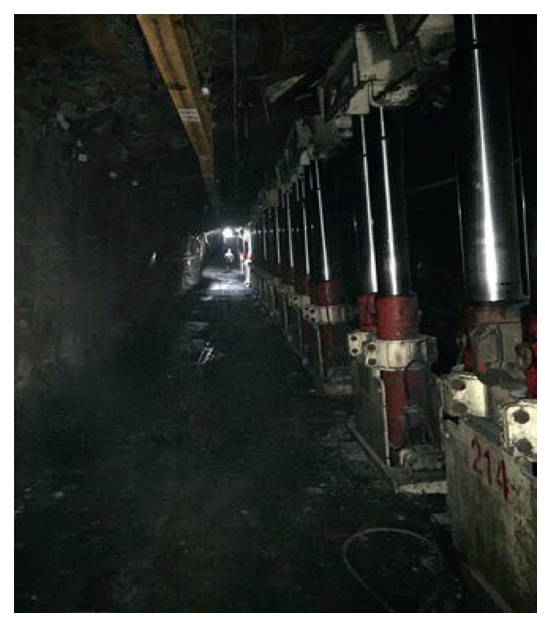

(c)

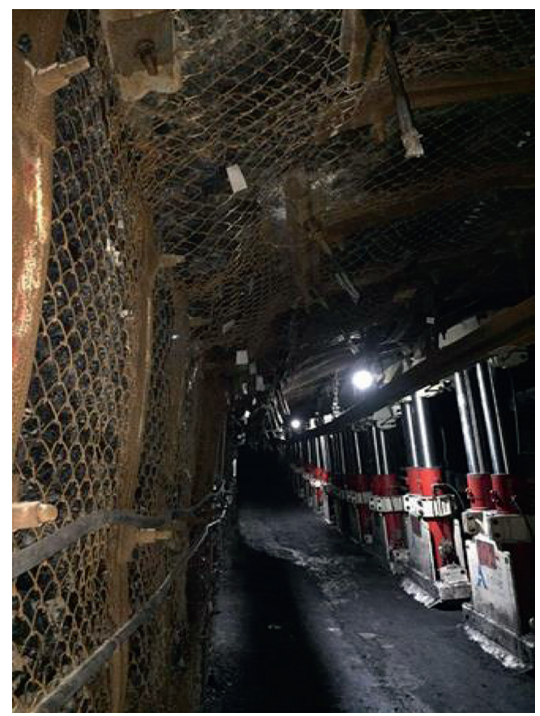

(f)

FIGURE 13: Site photographs of the implementation of surrounding rock control technology for retaining roadway along goaf. (a) Construction of blasting drilling. (b) Explosive assembly. (c) Pile support advance support. (d) Erection of gangue retaining column. (e) Actual effect of gangue retaining. (f) Effect of Retaining Roadway along goaf.

\section{Conclusions}

(a) The characteristics of blasting crack formation in hard rock are analyzed, and the mechanism of presplitting blasting crack formation in hard rock is revealed. Aiming at extrathick and hard rock stratum, the roof cutting technology of deep hole and shallow hole combined presplitting blasting is developed. The economic and reasonable blasting parameters are determined, and the purpose of changing the surrounding rock structure and improving the surrounding rock stress distribution is realized.

(b) For hard roof, deep holes and shallow holes with small spacing and parallel to each other shall be arranged on the planned seam line. Control the charge quantity of each blast hole and select explosives with low density and low detonation velocity. The uncoupled charge structure is adopted and detonated at the same time, so that the explosion action of the explosive just produces the through crack on the connecting line of the blast hole. The deep hole cuts off the deep rock stratum, and the shallow hole cuts off the shallow rock stratum.

(c) The peeping results show that during deep hole blasting, the crack forming rate in the charging section exceeds $85 \%$, and the blasting crack forming effect is good. In shallow hole blasting, the crack forming rate in the charging section exceeds 90\%, and the blasting crack forming effect is good. The deep hole and shallow hole are combined for evaluation. The drilling depth is $17.8 \mathrm{~m}$, and the joint length is more than $15.4 \mathrm{~m}$. Symmetrical cracks are obvious, and the crack forming rate is $87 \%$, indicating that presplitting blasting can form directional cracks in the roof and form structural weak planes, which is conducive to roof fracture and achieve the purpose of presplitting blasting. 
(d) The surrounding rock structure and stress distribution characteristics, gangue movement, and crushing expansion characteristics in goaf, and the dynamic mechanism of U-shaped steel sliding are studied. The surrounding rock control technology system of Retaining Roadway along goaf with roof cutting and pressure relief is developed, and the ground pressure behavior law of Retaining Roadway along goaf with roof cutting and pressure relief is determined. The control technology of retaining roadway surrounding rock with huge thick hard roof slab along the goaf has been formed with the core of "advanced precrack cutting joint $\longrightarrow$ roof reinforcement support $\longrightarrow$ gangue retaining protection beside the roadway $\longrightarrow$ lagging temporary support."

\section{Data Availability}

Some or all data, models, or code that support the findings of this study are available from the corresponding author upon reasonable request.

\section{Conflicts of Interest}

The authors declare that there is no conflict of interest regarding the publication of this paper.

\section{Acknowledgments}

This work was financially supported by State Key Laboratory of Water Resource Protection and Utilization in Coal Mining (GJNY-18-73.16), Support plan for scientific and technological innovation talents in Colleges and universities of Henan Province (21HASTIT024), Scientific and technological innovation research team of Henan Polytechnic University (T2021-5), National Natural Science Foundation of China (51974105), the Fundamental Research Funds for the Universities of Henan Province (Grant no. NSFRF200332), Key Research and Development and Promotion of Special (Science and Technology) Project of Henan Province (No. 212102310379), the Key Scientific Research Project Fund of Colleges and Universities of Henan Province (Nos. 21A610005 and 20B440001) and the Doctoral Foundation of Henan Polytechnic University (No. B201922). The authors appreciate the support.

\section{References}

[1] W. Shen, G. Shi, Y. Wang, J. Bai, R. Zhang, and X. Wang, "Tomography of the dynamic stress coefficient for stress wave prediction in sedimentary rock layer under the mining additional stress," International Journal of Mining Science and Technology, vol. 31, no. 4, pp. 653-663, 2021.

[2] S. Gong, "Investigation of tensile and fracture mechanical properties of bituminous coal at different strain rates," Journal of Materials Research and Technology, vol. 15, pp. 834-845, 2021.

[3] B. B. Dai, H. B. Li, S. J. Zhang, L Fan, J. F Cui, and W. J Wang, "Numerical simulation on stability of surrounding rock in deep hard rook tunnel induced by mining," Metal Mine, vol. 2020, no. 4, pp. 70-75, 2021.
[4] S. H. Li, L. J. Wang, and Z. Y. Liu, "Stability analysis and structural parameter optimization of test stope for complex broken ore deposit," Metal Mine, vol. 8, pp. 41-45, 2021.

[5] J. Zuo, J. Wang, and Y. Jiang, "Macro/meso failure behavior of surrounding rock in deep roadway and its control technology," International Journal of Coal Science \& Technology, vol. 6, no. 3, pp. 301-319, 2019.

[6] B. Wang, F. Dang, W. Chao, Y. Miao, J. Li, and F. Chen, "Surrounding rock deformation and stress evolution in predriven longwall recovery rooms at the end of mining stage," International Journal of Coal Science \& Technology, vol. 6, no. 4, pp. 536-546, 2019.

[7] Z. Guo, Q. Wang, S. Yin et al., "The creep compaction behavior of crushed mudstones under the step loading in underground mining," International Journal of Coal Science \& Technology, vol. 6, no. 3, pp. 408-418, 2019.

[8] J. Wang, S. Yang, W. Wei, J. Zhang, and Z. Song, "Drawing mechanisms for top coal in longwall top coal caving (LTCC): a review of two decades of literature," International Journal of Coal Science \& Technology, vol. 23, 2021.

[9] J. Wang, J. Yang, F. Wu, T. Hu, and S. A. Faisal, "Analysis of fracture mechanism for surrounding rock hole based on water-filled blasting," International Journal of Coal Science \& Technology, vol. 7, no. 4, pp. 704-713, 2020.

[10] Z. Y. Song, H. Konietzky, and X. Cai, "Modulus degradation of concrete exposed to compressive fatigue loading: insights from lab testing," Structural Engineering \& Mechanics, vol. 78, pp. 281-296, 2021.

[11] X. Chen, X. L. Liu, E. Z. Wang, and S. J. Wang, "Prediction and classification of strain mode rockburst based on five-factor criterion and combined weight-ideal point method," Chinese Journal of Geotechnical Engineering, vol. 39, no. 12, pp. 2245-2252, 2017.

[12] Q. G. Hu, F. M. Chen, and G. Z. Ning, "Rockburst evaluation model and application of CW-TOPSIS," Journal of Shandong University, vol. 47, no. 2, pp. 20-25, 2017.

[13] S. H. Li, S. Y. Wang, J. D. Zhu, B. Li, J. Yang, and L. Z. Wu, "Prediction of rockburst tendency based on weighted fusion and improved cloud model," Chinese Journal of Geotechnical Engineering, vol. 40, no. 6, pp. 1075-1083, 2018.

[14] F. Q. Gong, X. B. Li, and W. Zhang, "Rockburst prediction of underground engineering based on Bayes discriminant analysis method," Rock and Soil Mechanics, vol. 31, no. Supp.1, pp. 370-377, 2010.

[15] L. Luo and P. Cao, "Model of weighted distance discriminant analysis and application for deep roadway," Journal of Central South University, vol. 43, no. 10, pp. 3971-3975, 2012.

[16] S. C. Wu, Z. G. Wu, and C. X. Zhang, "Rockburst prediction probability model based on case analysis," Tunnelling and Underground Space Technology, vol. 93, pp. 1-15, Article ID 103069, 2019. 